\title{
Polítics per als nous temps. La nova classe política i les seves identitats
}

\author{
MARTí MARÍN CORBERA \\ Universitat Autònoma de Barcelona
}

\begin{abstract}
Resum: L'article avalua el grau d'identificació amb el règim franquista del personal que va formar-ne part durant l'etapa d'imposició. Per analitzar-lo, distingeix els criteris amb què fou reclutat aquest personal i qui en va tenir la responsabilitat, i construeix un seguit de càlculs estadístics elementals sobre l'origen social i polític dels individus que ocuparen, finalment, càrrecs de responsabilitat local entre 1939 i 1951. Com a passes prèvies per avaluar el sistema de presa de decisions i dels resultats que se'n derivaren, l'article descriu, també, un seguit de qüestions contextuals imprescindibles; així, concreta quina mena de collectiu s'està analitzant (la classe política local d'un règim, no d'un període) i delimita les circumstàncies polítiques de la postguerra espanyola i les dinàmiques que tingueren lloc a Catalunya. Les conclusions duen l'autor a afirmar, d'una banda, que un personal polític de contrastada fidelitat (per orígens polítics, però, sobretot, per implicació activa durant la guerra) ocupà sistemàticament els càrrecs de l'Administració municipal a Catalunya al servei d'un règim amb què no podia sinó sentir-s'hi identificat, i de l'altra, que aquesta fidelitat es concretà simbòlicament en l'afiliació massiva d'aquests individus dins el partit únic del règim, FET y de las JONS.
\end{abstract}

Paraules clau: Franquisme, Catalunya, postguerra, personal polític, Falange, Administració local

Abstract: The article assesses the degree of identification with Franco's regime in terms of the staff that worked within the regime during the period of imposition. To conduct this analysis, the article identifies the criteria with which this staff were recruited and who was responsible for the selection process, before going on to construct a series of elementary statistical calculations regarding the social and political origins of the individuals that eventually held positions of local responsibility between 1939 and 1951. As prior steps for the evaluation of the decision-making system and the results obtained, the article also describes a series of crucial contextual issues in order to specify the type of collective being analysed (the local political class of a regime, not a period) and establish the political circumstances of the Spanish post-war period and the dynamics that came to pass in Catalonia. The conclusions lead the author to assert that political staff with a proven track record of loyalty (in terms of their political origins but, above all, their active involvement during the civil war) were systematically entrusted with positions of municipal authorities in Catalonia in the service of a regime that they were certain to identify with. The article goes on to conclude that this loyalty was consolidated symbolically in the mass affiliation of these individuals to the regime's sole party, FET and the JONS.

Keywords: Francoism, Catalonia, post-war, political staff, Falange, local authorities

\section{Introducció}

Amb un títol que pot semblar més o menys adequat, aquest escrit pretén, d'una banda, tractar unes quantes temàtiques bàsiques sobre la classe política del franquisme català i a Catalunya durant la postguerra amb 
l'objectiu d'analitzar primer fins a quin punt s'identificà amb el règim el personal que va formar-ne part durant l'etapa d'imposició i que seria responsable de gestionar-ne la política; d'assenyalar després els criteris amb què aquest personal fou reclutat i aquells qui en foren responsables, i, finalment, de destriar d'on sorgiren políticament i socialment els centenars i centenars d'individus que componen el que hem anomenat classe política del franquisme català i a Catalunya. D'una altra banda, l'article documenta amb les dades disponibles sobre alcaldes i regidors fonamentalment la tercera de les tres qüestions anteriors, com una manera biogràfica d'acostar-se a la seva identitat. Atès que sobre les dues primeres qüestions no hi pot haver el mateix tipus d'aportacions documentals biogràfiques sinó que cal avaluar dinàmiques, valdrà la pena d'abordar, com a introducció, algunes coordenades bàsiques que són fonamentals quan s'analitza la classe política d'un període i, molt en particular, quan es tracta d'un període dictatorial. Perquè les dictadures tenen la capacitat sinistra de distorsionar la visió de les coses fins i tot després de mortes.

La meva primera publicació sobre personal polític franquista data de 1991; la darrera — descomptant aquesta - es pot llegir a Falange. Las culturas políticas del fascismo en la España de Franco. ${ }^{1}$ Vint anys de recerca al voltant d'aquest aspecte del període dictatorial -inclòs un grapat d'entrevistes en profunditat amb persones prou variades que formaren part de la classe mitjana d'aquest personal polític: alcaldes, regidors, periodistes locals, etc. - en particular a Catalunya, em permeten el luxe - i ja m'ho disculparan - d'iniciar aquest article amb algunes reflexions motu propio sense haver de recórrer a excessives citacions d'autoritat: em valdré de la dita que la veterania és un grau.

L'expressió "classe política" que figura en el títol resulta extremadament equívoca, per començar. D’ús generalitzat en els nostres dies, evoca un sector social que ha fet de la política la seva activitat vital i/o professional primordial per mitjà de l'ocupació de càrrecs retribuïts en l'estructura de l'Estat — central, perifèric, autonòmic i local — o en l'organització interna dels partits polítics, tot i possibles períodes d'ostracisme: una

1 Martí Marín, «L'Ajuntament de Sabadell en el període franquista: l'articulació política municipal, 1939-1979», Arraona. Revista d'Història 9 (1991): 81-94, i «Falange y poder local», dins Miguel Ángel Ruiz Carnicer, ed., Falange. Las culturas políticas del fascismo en la España de Franco (19361975) (Zaragoza: Institución Fernando el Católico, 2012), 231-252. 
manera especial de burocràcia elegida per la ciutadania o designada pels dirigents electes dels partits, per comptes de filtrada a través d'un sistema d'oposicions lliure o restringit. Els seus límits resulten imprecisos, especialment quan algú fa la proposta — prou assenyada — d'incloure en la nòmina els activistes dels moviments socials o certs personatges del que els mitjans de comunicació de masses anomenen, no menys equívocament, "societat civil". Tot plegat remet a una forma d'Estat complex i regit per normes necessàriament democràtiques —en major o menor mesura - , que opera sobre una societat no menys complexa — ni menys democràtica - en la qual diverses opcions competeixen en un sistema de concurrència imperfecte per fer-se amb el control de responsabilitats parcials de govern. Aquestes opcions poden aspirar no només a reemplaçar-se les unes a les altres en l'exercici del govern, sinó també a impugnar el sistema de govern en ell mateix. A l'hora de determinar la classe política del franquisme, però, bona part d'aquests supòsits s'esvaeix: ni diversitat d'opcions, ni concurrència, ni elegibilitat, ni moviments socials, ni societat civil independent de l'Estat. Només podem comptar amb aquelles persones que han ocupat càrrecs governamentals i ens cal excloure qualsevol oposició. Dit d'una altra manera: la classe política franquista, a diferència de l'actual, de la classe política de la Segona República o de la monarquia liberal, només fa referència al Govern; no és la classe política d'un període sinó la d'un règim. I això significa també que intellectuals — periodistes inclosos-, càrrecs sindicals, responsables d'entitats culturals, recreatives, etc., mantenien en el franquisme un caràcter vicari dels càrrecs polítics que els fa completament subordinats i no complementaris, alternatius o diferenciats d'alguna manera de la classe política en sentit estricte. ${ }^{2}$

Aquesta precisió, que hom podria trobar òbvia, no resulta pas intranscendent, ja que, quan no es té prou en compte, condueix irreparablement

2 Ha estat prou ben analitzat com, precisament en el cas dels periodistes, els matisos en els discursos que podien emetre mantenien un inequívoc comú denominador que converteix en absurda tota divisió entre fidels i dissidents al règim: si treballaven en la legalitat i de cara al públic no hi podia haver espai per a cap dissidència, malgrat algunes equívoques fames de liberal construïdes posteriorment. Vegeu Francesc Vilanova, La Barcelona franquista i l'Europa totalitària (1939-1946) (Barcelona: Empúries, 2005), i Francesc Vilanova \& Laia Arañó, Un mundo en guerra. Crónicas españolas de la Segunda Guerra Mundial (1939-1946) (Barcelona: Destino, 2008). Per a un cas de cronologia ben posterior vegeu Martí MARÍN, «El catalanisme franquista: Josep Pla i l'operació Porcioles», dins Jordi LaRios, ed., La cara fosca de la cultura catalana (Palma: Lleonard Muntaner, en premsa). 
a trobar dins de la dictadura analitzada una pluralitat impossible; problema que ha afectat i afecta de manera molt especial els estudis que es fan sobre el règim franquista. Quan es tracta de la classe política d'una dictadura no hi ha oposició que pugui integrar-se en l'anàlisi: podem trobar heterodòxies, dissentiments parcials i alguna que altra posició incòmoda més, però en cap cas podem descobrir representada dins de la dictadura una alternativa a aquesta, precisament perquè les dictadures - i no només les feixistes - no admeten alternatives. Ignorar aquest fet, fins i tot en situacions en què es jutja innecessari de remarcar-ho, ha provocat que es prengués com a opositors individus que no exercien cap mena d'oposició, i que s'oblidés on estava ubicada realment l'oposició, això és, extramurs de la classe política que s'estava analitzant. En definitiva, ha provocat que es trobés dins del règim tot allò que necessàriament s'ubicava fora, i que es fessin concepcions sobre el període franquista en les quals una part - el règim - ocupava el lloc del tot - la formació social espanyola o catalana. O pitjor encara, ha motivat que es comparés aquest període amb d'altres, sense parar esment que el tipus de relació que s'establia entre poder i oposició en un i altre períodes no tenia, en absolut, la mateixa naturalesa.

D’aquesta manera, la constatació banal que «la República també reprimia» o que en els seus anys d'exercici hi hagué situacions de violència - de quin període o sistema podríem dir el contrari? - , ha permès a alguns oblidar que la República no empresonava o executava sistemàticament els seus opositors - ni tan sols durant la Guerra Civil, si descomptem l'excepcionalitat de l'estiu de 1936, en el marc ja prou excepcional del que significa una guerra-, i que aquests, tot sovint, varen poder disposar de locals, òrgans de difusió, possibilitats d'activitat pública i, fins i tot, escons parlamentaris i algun que altre ministeri. José Antonio Primo de Rivera, José María Gil-Robles o Antonio Goicoechea poden integrar-se en un estudi sobre la classe política de la Segona República perquè efectivament hi varen pertànyer; mai no he vist, en canvi, que a l'hora d'explicar la classe política del franquisme ningú hi inclogui Dolores Ibárruri, Indalecio Prieto o Josep Tarradellas, posem per cas.

Obviant unes diferències tan impossibles d'arraconar, les mal anomenades oposicions internes s'han plantejat com si fossin alternatives de govern oblidant que, en darrera instància, en el franquisme el Govern 
era el dictador i que, com a màxim, aquests grups en pugna a l'interior del sistema podien postular-se com a recanvis per als seus subordinats en exercici, però no com a recanvis de Franco. ${ }^{3} \mathrm{Ni}$ el seu càrrec ni les seves prerrogatives estaven en discussió dins del règim, sempre que ell no decidís cedir-les. Entre aquestes hi havia l'exercici directe del govern sense limitacions; un govern que podia delegar competències o funcions als seus ministres però mai de manera completa: els ministres de Franco eren seleccions de subordinats, com ho eren els càrrecs inferiors dels ministeris respecte dels ministres mateixos en un escalafó fèrriament jerarquitzat. Atès això, tractar com a opositors a grups que tan sols aspiraven a reemplaçar-se mútuament com a servidors del dictador resulta completament fora de lloc; excepte si per comptes d'oposició entenem que estaven fent alguna mena d'«oposicions».4

Cal deixar molt ben assentat aquest punt de partida perquè, normalment, la discussió del paper del dictador en una dictadura no ha estat sinó un símptoma de descomposició i l'anunci anticipat de la seva fi, fins i tot, com en el cas espanyol, quan aquesta discussió es va produir diferida en qualsevol concreció al moment del traspàs de Franco. ${ }^{5}$ Per afrontar la posada en marxa del règim a Catalunya en la postguerra, moment en el qual el seu paper estava encara acabant-se de dibuixar, qualsevol consideració

3 Ningú no ha plantejat mai seriosament que l'objectiu últim dels sectors polítics integrats en el règim fos reemplaçar Franco — objectiu d'una veritable oposició—, sinó, en tot cas, ocupar espais de poder a la seva ombra i, molt tardanament, posar damunt de la taula opcions per reorganitzar el règim a la seva mort, sense qüestionar —ni tan sols— les seves disposicions successòries. Vegeu, per exemple, Sheelagh Ellwood, Prietas las filas. Historia de Falange Española, 1933-1983 (Barcelona: Crítica, 1984); Javier TuSELL, Franco y los católicos: la política interior española entre 1945 y 1957 (Madrid: Alianza, 1984), i José Antonio Olmeda Gómez, Las Fuerzas Armadas en el Estado Franquista (Madrid: El Arquero, 1988). El trist paper dels pseudoconspiradors militars del final de la Segona Guerra Mundial es pot seguir a Paul Preston, Franco. Caudillo de España (Barcelona: Grijalbo, 1994), 602-663.

4 Manllevo la broma al títol que va posar Jaume Sobrequés a la biografia del seu pare — amb un sentit de l'humor molt personal-, 1941. Un opositor català durant el franquisme (Barcelona: Ed. Base, 2005). A la presentació de les cobertes, per evitar equívocs aclareix: «Un jove d'aquesta ciutat [Girona], que ha fet la guerra en l'exèrcit republicà, intenta, a Madrid, en unes dures oposicions a càtedra, després d'un primer fracàs l'any anterior, refer allò que la guerra i les seves conseqüències li havien pres. Un lloc estable de professor a l'Institut de la seva ciutat natal».

5 A partir de la posada en marxa de les disposicions combinades de la Ley de Sucesión (1947) i de la Ley Orgánica del Estado (1966), especialment de 1969 ençà, amb la designació de Juan Carlos de Borbón com a successor a títol de rei, tots els debats interns sobre associacions, elegibilitat, vot, etc., i la seva manca de resultats tangibles implicaven aquesta descomposició. Vegeu Carme Molinero \& Pere Ysàs, La anatomía del franquismo. De la supervivencia a la agonía, 1945-1977 (Barcelona:Crítica, 2008). 
de les que legítimament es poden fer a les acaballes de la dictadura sobre la preparació de l'endemà resulten del tot extemporànies: en la immediata postguerra es podien prendre posicions darrere de Franco — dins del règim - o contra Franco - extramurs. Pensar a reemplaçar-lo des de dins, fins i tot a mitjà termini, era quelcom que no podia ni tan sols insinuar-se i que, per tant, aparegué puntualment com a reacció al desenllaç de la Segona Guerra Mundial i prou, al caliu d'alguna que altra mort violenta d'algun que altre dictador proper que, a la fi, no tingué conseqüències per a Espanya. En aquest sentit ja resulta prou extemporània — si no ridícula - la pretensió de Manuel Ortínez en les seves memòries, on afirma que «La majoria d'aquelles sobretaules a Palafrugell [amb Josep Pla] tenien com a objectiu primordial l'elaboració del primer Govern després de Franco», ${ }^{6}$ quan ja havia iniciat la ruta que el portaria a exercir com a collaborador del règim, especialment tenint en compte que es refereix als primers cinquanta i que resulta una excusatio non petita, atès el que després acabaria acceptant. Es tracta, en definitiva, d'una actitud molt comuna entre aquells que han assegurat obstinadament que varen poder fer oposició des de dins a Franco. Des d'una posició molt diferent, també en va haver que, escoltant La Pirenaica, es varen creure moltes vegades que Franco tenia els dies comptats. Anys després, però, ho han recordat si més no com una prova de la seva manca de perspectiva o de la necessitat de tenir alguna esperança per continuar la lluita, i no de la seva perspicàcia.

Si deixem de banda paraules tan gruixudes com "oposició" i les reservem per qualificar als que exerciren tal paper de manera efectiva allà on veritablement era possible fer-ne - o al menys, intentar-ho-, el que sí que podem trobar són les lògiques diferències d'opinió i d'opció que dins del personal polític d'una dictadura puguin haver-hi sobre un tema determinat, i que existeixen sempre perquè cap sistema no garanteix la unanimitat a priori i perquè tot sistema polític conté marge de maniobra en qüestions que no siguin fonamentals. La discussió interna sí que va existir dins del franquisme, sempre subordinada a un dictador que tenia la darrera paraula (autarquia o desarrollo, gironazos o convenis collectius, etc.); però de discussió interna en podem trobar dins del règim nazi i dins, també, de l'estalinisme en les mateixes condicions i amb el ma- 
teix tipus d'àrbitre en darrera instància. Ser opositor a una dictadura, per tant, significa tenir com a objectiu que es dissolgui, i no expressar una opinió diferent davant dels problemes que se li puguin plantejar: només les democràcies han demostrat ser prou plurals per admetre dins de la seva estructura polítics en exercici que pretenguin liquidar-la i, encara, no sempre. No podem començar l'anàlisi de la classe política, d'ara endavant personal polític franquista català i a Catalunya, sense tenir en compte aquestes circumstàncies generals que ni ens diuen qui eren els que en formaven part ni per què ho feien, però que sí que ens informen sobre el que de cap manera no podien ser (això és, opositors) i sobre el que de cap manera no podien pretendre (és a dir, l'enderroc del règim). Per poder fer, ara, una primera passa en positiu i veure l'índex d'identificació que tenia el personal polític amb el règim, amb quins criteris fou reclutat $\mathrm{i}$ per qui, ens cal valorar, a continuació, les circumstàncies polítiques específiques de la postguerra a Catalunya.

\section{Les circumstàncies polítiques de la postguerra a Catalunya}

En alguna ocasió m’he referit a la situació de la Catalunya de 1939 com un veritable desert polític en termes organitzatius que va ser reestructurat per les forces d'ocupació a partir de la «comunitat de la Victòria», a la qual s'havia integrat un nombre gens negligible de catalans. ${ }^{7}$ Valdria la pena oferir un quadre complet d'aquestes circumstàncies perquè la interpretació en resulti inequívoca. Abans de res cal referir-se a l'exclusió dels vençuts de la Guerra Civil en els seus justos termes. Massa sovint s'ha interpretat que l'expressió segons la qual Catalunya «va perdre la guerra» era poc menys que literal, de la mateixa manera que en termes espanyols s'ha convertit en literal la no menys falsa expressió de l'enfrontament entre «media España contra la otra media». Ni una cosa ni l'altra són veritat i el fet que siguin formulacions tan esteses ens avisa de la més que notable desinformació que hi ha - fins i tot, entre alguns investigadors del franquisme- sobre la vida política del període republicà en temps de pau. ${ }^{8}$

7 Martí Marín, Josep Maria de Porcioles. Catalanisme, clientelisme, franquisme, segona edició corregida (Barcelona: Base, 2005), 50.

8 Una actualització d'urgència amb l'argumentació seguida fins aquí de no magnificar la divisió en dos durant els anys 1931-1936 es pot seguir a Martí MARín, «La II República y la Guerra Civil 
En termes polítics estrictes, les forces vencedores de la Guerra Civil no representaven ni mitja Espanya ni gairebé una quarta part. Altra cosa és que fossin capaces d'arrossegar darrere seu seguidors d'altres opcions polítiques un cop iniciades les hostilitats per la via del cop d'estat. Per posar-ne només un exemple, a les Corts sorgides de les eleccions de febrer de 1936 la suma dels diputats de FE-JONS, la Comunión Tradicionalista, Renovación Española, el Bloque Nacional i la resta de grups i grupuscles que l'abril de 1937 quedarien unificats dins FET-JONS, eren només 30 de 473, cap del quals falangista (això és, doncs, 6,3\% del total). Fins i tot si hi sumem els diputats de la CEDA — cosa no del tot correcta perquè alguns d'ells foren veritables demòcrates conservadors que no s'unirien al franquisme, com Luis Lucia o Manuel Giménez Fernández-, la xifra ascendeix a 118 de 473, o sigui el 24,9\%. Si bé és cert que el sistema electoral majoritari fa que això no reflecteixi que representaven un percentatge de vots emesos bastant superior, tampoc no es pot exagerar fins a parlar del mític 50\% d’Espanya - al marge que calgués comptar el 20\% llarg d'abstencionistes, que també existien-, ja que a moltes províncies la candidatura de les dretes, per a la qual sortiren elegits els diputats de la CEDA, va incloure el Partido Agrario de Martínez de Velasco, la Lliga Catalana de Cambó, el Partido Liberal Democrático de Melquíades Álvarez i altres formacions conservadores que no havien estat contràries a la República per principi i que no varen prendre part en el cop d'estat, sinó que, ben al contrari, de febrer a juliol de 1936 exerciren com a lleial oposició parlamentària. A les urnes un nombre gens negligible de ciutadans i ciutadanes optà, igualment, per opcions centristes com el Partit Republicà Radical de Lerroux — que encara obtingué 6 escons-, els republicans conservadors de Niceto Alcalá-Zamora — també 6 - o el Partido del Centro de Portela Valladares - que n'acumulà 17. Entre uns i altres sumaren 69 diputats, més del doble que l'extrema dreta colpista.

La presumpta divisió en dos de l'Espanya republicana s'ha mistificat fins a un punt intolerable, com si hagués estat la causa i no l'efecte de la guerra, sense parar esment en el caràcter de conglomerat, a voltes poc

(1931-1939)», dins Joan Fuster, ed., Historia de España contemporánea (Barcelona: UOC, 2009). En qualsevol cas, el millor contrapunt per no menystenir les llavors del conflicte és el magnífic llibre de Julián CaSanova, República y guerra civil, dins Josep Fontana \& Ramón Villares, dir., Historia de España, vol. viII (Barcelona: Crítica/Marcial Pons, 2007). 
congruent i sempre forçat per les servituds d'un sistema electoral majoritari, que foren els dos grans cartells electorals de febrer de 1936: l'Espanya i la Catalunya de 1936 estaven dividides, efectivament, però no en dos. Acabada la guerra - per si de cas-, els vencedors no pensaren ratificar popularment ni el suport que tenia el seu model d'Estat, que es trobava en construcció, ni la seva nova fórmula política unificada (FETJONS). Malgrat la seva pretesa pluralitat interna, els vencedors no pensaren, tampoc, comprovar quines de les seves peces constitutives gaudien de major suport popular. Preferiren donar per bona la cínica formulació segons la qual el conflicte havia estat un «plebiscito armado» i mantenir la ficció que gaudien d'un suport majoritari indiscutible, tot i ser ben conscients que això no era pas així, tal com han revelat en múltiples ocasions informes interns dels diversos aparells del règim. ${ }^{9}$

Passant a la qüestió catalana, el tema pot plantejar-se d'una manera similar però desmentint el mite contrari. Efectivament, els vencedors, comptats en termes de representació política prèvia al conflicte armat, no significaven mitja Catalunya ni de bon tros, però tampoc no eren tan irrellevants per suggerir una Catalunya unànimement derrotada. La Comunión Tradicionalista havia arribat a tenir 2 diputats (Lleida i Tarragona, 1933), resultats que es corresponien al pes tradicional del món carlista-integrista al Principat des de principi de segle. Els carlistes i els vots de les dretes espanyolistes a Catalunya no representaven ni gaire més ni gaire menys que el que hem vist que representaven al conjunt espanyol, per tant. Però la Lliga Catalana (22 diputats el 1933 i 12 el 1936) havia acabat donant suport a les armes de Franco amb diners, logística i avals internacionals des del primer moment del conflicte, encara que en temps de pau hagués passat per etapes de clara adaptació al marc republicà. ${ }^{10}$

9 Per exemple, a Catalunya, els informes de la Delegación Nacional de Provincias de FET y de las JONS de la més immediata postguerra, que va utilitzar per primera vegada Borja de RIQUER, «Un país després d'una guerra (1939-1959)», dins Borja de RiQueR \& Joan B. Culla, coord., El franquisme i la transició democràtica, 1939-1988, «Història de Catalunya» VII (Barcelona: Edicions 62, 1989), 140-144.

10 Sobre les anades i vingudes de la Lliga entre l'acatament i l'hostilitat a la República, vegeu Borja de RiQuer, L'últim Cambó (1936-1947). La dreta catalanista davant la Guerra Civil i el franquisme (Vic: Eumo, 1996); Francesc Cambó: entre la monarquia i la república (1930-1932) (Barcelona: Base, 2007), i Alfons XIII i Cambó, unes relacions difícils (Barcelona: Reial Acadèmia de Bones Lletres de Barcelona, 2008). 
L'abandonament de la Lliga de les seves posicions liberalconservadores - cosa que a Espanya no féu la Unión Republicana que liderava Diego Martínez Barrio, tot i que bona part dels seus membres havien donat suport als governs del Bienni Negre, per exemple-, s'ha volgut justificar exclusivament com una conseqüència de la revolució i dels actes anticlericals de l'estiu de 1936. Però l'experiència d'Unió Democràtica de Catalunya ens mostra com l'opció de la Lliga fou política i no pas cap mena de resultat natural dels esdeveniments en curs: ningú no ha suggerit mai ni que la UDC es transformés en revolucionària ni que fos menys catòlica que la Lliga. ${ }^{11}$ Com és natural, acabada la guerra, el règim no posà atenció en representativitats obtingudes electoralment i remarcà els marges de la victòria acudint a l'expedient repressiu sobre les zones d'ombra, no vençudes però tampoc acceptables com a vencedores segons els estàndards nacionales, per més conservadores que fossin. Reprimir polítics i personalitats de l'espai conservador - àdhuc catòlic - resultà funcional per delimitar més clarament el terreny de joc, i serví perfectament com a avís per a navegants, tant a Catalunya com al País Valencià o a Palència. ${ }^{12}$ Els franquistes ni eren ni volien ser confosos amb el conservadorisme tradicional, per més catòlic que fos. ${ }^{13}$

11 La trajectòria d'UDC durant laguerra encara no està prou ben analitzada, tanmateix. Per a la seva plana major comptem amb l'obra d'Hilari RAguer, La Unió Democràtica de Catalunya i el seu temps (1931-1939) (Barcelona: Publicacions de l'Abadia de Montserrat, 1976). Des de fora de l'àmbit acadèmic, resulten molt interessants els volums de les memòries de Maurici SERrahima, Memòries de la guerra $i$ de l'exili, 2 vol. (Barcelona: Edicions 62, 1978 i 1981). Per no confondre Església catòlica amb una opció concreta de partit, vegeu Hilari RAGUER, La pólvora y el incienso. La Iglesia y la Guerra Civil españo la (1936-1939) (Barcelona: Península, 2001), així com les interessants reflexions de Santos Juliá, «Catolicismo frente a laicismo», dins Manel RisQues, coord., Visca la República! (Barcelona: Proa, 2007).

12 Vegeu, per exemple, Francesc Vilanova, Repressió política i coacció econòmica. Les responsabilitats polítiques de republicans $i$ conservadors catalans a la postguerra, 1939-1942 (Barcelona: Publicacions de l'Abadia de Montserrat, 1999). La repressió sobre conservadors i sectors diversos de la dreta tinguts per poc segurs fou relativament freqüent durant la guerra i la postguerra, no només a Catalunya, en funció de les circumstàncies. Per al processament el febrer de 1939 dels membres conservadors i liberals de la comissió gestora de Palència de juliol-agost de 1936 - nomenada pels propis colpistes- vegeu Domingo García Ramos, Instituciones palentinas durante el franquismo (Palència: Diputación de Palencia, 2005), 255-258. Sobre la condemna a trenta anys del líder de la DRV Luis Lucia, vegeu Rafael VALLs, La Derecha Regional Valenciana (1930-1936) (València: Edicions Alfons el Magnànim, 1992), 246-248. Vegeu, també, un exemple de detencions d'antics cedistes de primera fila el desembre de 1944 a Paul Preston, Franco. Caudillo de España, 649-650.

13 Sobre la impossible existència de "conservadors tradicionals" actius dins del règim franquista vegeu Martí MARÍN, «Els governadors civils del primer franquisme: sis personatges en busca d'autor», 
L'expressió que citava més amunt sobre el «desert polític» català de 1939 s'ha d'entendre, en primer lloc, com una situació creada per l'absència forçada dels vençuts catalans, que eren la majoria -en atenció als resultats electorals de 1931-1936 - i, en segon lloc, per la pregunta, no resolta, sobre a qui reconeixerien les autoritats d'ocupació com a vencedors amb capacitat de participació política. La decisió sobre qui era vencedor i qui no, sinònim de qui podria participar de la vida política legal, corresponia a les autoritats d'ocupació, en les quals hi havia també integrats alguns catalans, com ara Bertran i Musitu, Eugeni d'Ors, Pepe Ribas Seva, Eduard Aunós, Miquel Mateu, etc. Ni una sola iniciativa autòctona era, doncs, possible sense el plàcet dels ocupants, ni a Catalunya ni enlloc, si no era la Delegació Territorial de la Falange Catalana acabada d'arribada de Burgos i installada a Barcelona - ara només com a Jefatura Provincial de FET $\mathrm{y}$ de las JONS de Barcelona - sota el comandament del manresà Mariano Calviño de Sabucedo y Gras. ${ }^{14}$ Però aquest sector polític - ben català si atenem als cognoms de Ribas Seva, Trias Bertran, Fontana Tarrats, etc.-, no era fàcil de diferenciar de les autoritats d'ocupació, car depenia en aquell moment de Ramón Serrano Suñer tant com en depenia el cap dels Servicios de Ocupación, el general Eliseo Álvarez-Arenas. Tampoc no era molt clar a qui incloïa i a qui excloïa aquesta nova FET-JONS, atès que, quan havia fet el trajecte invers, de Catalunya a Burgos, encara com a FEJONS estava integrada per poques dotzenes d'individus i no pas pels milers que ara assegurava englobar, i que aquests milers, retornats a poc a poc als seus pobles, exhibien indistintament carnets de militante, adherido, excombatiente, excautivo, caballero mutilado de España, etc., a l'hora de fer valer les prerrogatives del vencedor.

Aquesta situació de vigília es mantingué durant tot l'any 1939 i algunes circumstàncies - que tot seguit examinarem - concorregueren, en certs llocs de Catalunya, a no desencallar-la fins al 1940 o al 1941. Per po-

dins Pere Ysàs, ed., Actes del Congrés Internacional 1939. L'Any de les Catàstrofes, Barcelona, 22-24 d'abril de 2009, CD-ROM (Barcelona: UAB-CEFID/CCCB, 2009).

14 La seva història va ser detalladament analitzada per Joan Maria TномÀs, Falange, Guerra Civil $i$ franquisme. F.E.T. $y$ de las J.O.N.S. de Barcelona en els primers anys del règim franquista (Barcelona: Publicacions de l'Abadia de Montserrat, 1992). Grups encara més petits d'aquesta organització territorial catalana de Falange es convertirien en les delegacions provincials de Lleida, Tarragona i Girona, per ordre d'ocupació. 
der posar l'Administració sota control civil - encara que l'exercís un militar - calia, abans de res, que s'acabés la guerra, cosa que trigaria poc, i que es posessin en marxa, sistemàticament i per tot el territori, les prioritats clarament repressives que acompanyaven l'ocupació, des de les incautacions patrimonials a les depuracions de funcionaris, passant per les responsabilitats polítiques, els consells de guerra, etc. Per poder posar en marxa ajuntaments i diputacions, però, era urgent nomenar les autoritats locals provisionals abans i tot d'haver aclarit amb precisió qui podia formar-ne part encara que aquesta situació fomentés, en la majoria de les comissions gestores, una situació d'interinitat incòmoda. Els inicis estarien carregats, doncs, d'incerteses. ${ }^{15}$

Cal pensar, però, en una doble dinàmica, per dir-ho així: una que incidia en les grans línies de circulació de la influència política — ara restringida a molt poca gent - i una altra que implicava les fórmules de govern de proximitat que afectarien la gran majoria d'individus. La societat catalana de postguerra, com tota la societat espanyola, estava dràsticament dividida entre vencedors i vençuts, i els segons van saber des del primer moment que, si no podien fugir cap a l'exili —o si hi havien renunciat per qualsevol circumstància-, els calia posar-se a la defensiva i passar el més desapercebuts possible a les diverses autoritats, de les quals no podien esperar res de bo. Com sabem pels estudis de la repressió que s'han dut a terme fins ara, les execucions, l'empresonament, la deportació, les depuracions, etc., impediren aquest anonimat a una quantitat ingent de ciutadans. ${ }^{16}$ Per a la resta, el silenci.

En el món dels vencedors hi havia, també, categories internes. La gran burgesia catalana d'industrials, propietaris, financers, professionals liberals d'alt nivell, etc., tenia la vista fixada fonamentalment en la recuperació de les seves propietats i a engegar els seus negocis i activitats a plaer. Per aconseguir-ho hi havia les més altes autoritats i les comissions ad hoc

15 Martí Marín, Els ajuntaments franquistes a Catalunya. Política i Administració municipal, 1938-1979 (Lleida: Pagès, 200o), 84 i ss.

16 Vegeu Santos Juliá, ed., Víctimas de la Guerra Civil (Madrid: Temas de Hoy, 1999); Ricard Vinyes, Irredentas. Las presas políticas y sus hijos en las cárceles de Franco (Madrid: Temas de Hoy, 2002); Carme Molinero, Jaume Sobrequés \& Margarida SAla, ed., Una inmensa prisión. Los campos de concentración y las prisiones durante la Guerra Civil y el franquismo (Barcelona: Crítica, 2003), i Gutmaro Gómez Bravo, La redención de penas. La formación del sistema penitenciario franquista (Madrid: Los Libros de la Catarata, 2007). 
que aquestes havien organitzat. Quan aquests mecanismes es revelaren insuficients o ineficients, s'obriren petites crisis dins del sistema, que es trobava en formació a Catalunya, com he analitzat amb detall en altres ocasions. ${ }^{17}$ Foren, però, crisis de creixement que no afectaren de manera greu la posada en marxa de l'aparell franquista, perquè aquest reaccionà de manera taxativa fent respectar el principi jeràrquic..$^{18} \mathrm{El}$ mateix passava amb la burgesia petita i mitjana - la majoritària, numèricament parlant-, però amb la diferència que les possibilitats que tenia d'accedir a les altes autoritats eren irrisòries; s'havia de conformar amb les autoritats locals, aquelles que, precisament, estaven en una situació de precària provisionalitat, segons hem explicat. Les possibilitats d'èxit d'aquestes gestions eren sempre més petites i les de trobar un interlocutor alternatiu pràcticament nulles, amb la qual cosa la satisfacció devers el règim tendia a ser més baixa. Podríem continuar descendint en la piràmide social - en termes de capacitat adquisitiva - i fer les mateixes consideracions a escala entre altres nuclis de vencedors de condició més humil. Borja de Riquer ja va explicar en el seu moment com, en el cas català, aquesta escala social descendent es va reflectir també en una escala descendent de satisfacció i de suport al règim —-més recentment, ha recapitulat sobre el tema des d'un abast espanyol, amb conclusions anàlogues. ${ }^{19}$ Així doncs, el resultat fou que els canals de circulació de la influència política

17 Vegeu Martí Marín, «Els qui manaven», dins Borja de RIQuer, dir., Història, política, societat i cultura dels Països Catalans, x: La llarga postguerra, 1939-1959 (Barcelona: Enciclopèdia Catalana, 1997), 140-155, i «El nou poder local», dins Manel Risques, Francesc Vilanova \& Ricard VinYES, ed., Les ruptures de l'any 1939 (Barcelona: Fundació Carles Pi i Sunyer/Publicacions de l'Abadia de Montserrat, 2000), 55-67.

18 Per posar-ne només un exemple: quan un titular d'una capitania general, instat per algun empresari que hi recorria, feia gestions que no eren previstes dins de les seves atribucions i aprofitava l'avinentesa per treure'n una compensació a còpia de demanar-li adhesions a una determinada iniciativa política sortida d'ell mateix, Franco l'acabaria reemplaçant —és el cas d'Orgaz i de Kindeláni cercaria una via més adequada perquè les gestions es fessin allà on tocava, nomenant, per exemple, algun ministre català -Aunós, Carceller. La cursiva vol dir que Demetrio Carceller, a diferència d'Eduardo Aunós, no havia nascut a Catalunya tot i que s'hi havia format professionalment i política. Vegeu MARín, «El nou poder local».

19 Vegeu RiQuer, «Un país després d'una guerra (1939-1959)», 133-144; «Rebuig, passivitat i suport. Actituds polítiques catalanes davant el primer franquisme (1939-1950)», dins Francesco BARBAGAllo et al., Franquisme. Sobre resistència i consens a Catalunya (1938-1959) (Barcelona: Crítica, 1990), 179-193, i La dictadura de Franco, dins Josep Fontana \& Ramón Villares, dir., Historia de España, vol. Ix (Barcelona: Crítica/Marcial Pons, 2010), 179-245. 
quedaren tot sovint curtcircuitats, en absència encara d'una Administració organitzada i consolidada on les competències estiguessin clarament definides: perquè tothom que ho va necessitar va intentar saltar-se l'ordre jeràrquic d'un sistema que pretenia, per damunt de tot, funcionar de forma inequívocament jerarquitzada.

Així mentre a la patronal industrial, per exemple, li preocupava fonamentalment com establiria els seus nous contactes amb el Ministeri d'Indústria i Comerç o bé amb Franco mateix i menystenia tota la resta, els botiguers, per exemple, perquè es resolguessin les seves demandes, havien d'esperar que s'aclarís a l'ajuntament corresponent qui mereixia governar d'entre els diversos nuclis enfrontats de vencedors. D'aquesta manera, la normalització institucional arribaria d'una manera prou lenta i tindria uns primers resultats tant més ineficients com més es distanciava el problema de les altes esferes. Tanmateix, els vencedors no s'allunyaren pas de Franco per aquest motiu, sinó que s'adaptaren i es conformaren a comprovar que obtenien altres satisfaccions del règim i que no deixaven de ser privilegiats: la ineficiència, la lentitud, l'arbitrarietat i totes les disfuncions que la dictadura acumulà ràpidament no generaren desafecció, en termes pràctics i dietaris íntims al marge, entre els que havien donat suport i/o saludat la seva victòria. Les primeres desafeccions de vencedors no arribaren fins anys més tard i no foren pas generalitzades, ni de lluny.

El que aquí es planteja no és només com la recuperació de la dinàmica centralista de l'Estat espanyol contemporani — hom podria pensar tan sols que era una més - va comportar la reaparició dels problemes d'ineficiència propis del tombant de segle — poc o molt superats a còpia de major democràcia i de dosis de descentralització i autonomia política-, sinó com aquesta recentralització franquista va ser tan extrema, tan accentuada per la manca de democràcia i de tota mena d'elegibilitat dels càrrecs, que va fer entrar en collapse el conjunt de l'Administració perifèrica, i com a aquesta situació de crisi s'hi va arribar de seguida. ${ }^{20}$ Els càrrecs de govern del règim a Catalunya, abans que el personal polític no els ocupés de manera més o menys estable, varen quedar desproveïts

20 Aquesta és una de les tesis centrals que vaig defensar a MARín, Els ajuntaments franquistes a Catalunya, 55-198. Sobre el mateix tema vegeu Carme Molinero \& Pere Ysàs, «La Diputació de la postguerra, 1939-1949", dins Borja de RiQuer, dir., Història de la Diputació de Barcelona, 1812-2005, vol. III: 1939-2005 (Barcelona: Diputació de Barcelona, 2007), 9-45. 
per diversos motius de qualsevol mena d'instruments bàsics sense els quals no podien desenvolupar-se'n correctament les funcions: en primer lloc, perquè la seva capacitat d'actuació autònoma va ser despietadament eliminada d'acord amb la jerarquització de nomenaments i el furt de competències; ${ }^{21}$ en segon lloc, perquè les disponibilitats pressupostàries varen ser reduïdes a la mínima expressió per mitjà d'una veritable contrareforma fiscal, ${ }^{22} \mathrm{i}$, en tercer 1 loc, perquè el poc que va quedar dempeus havia de ser gestionat per un cos de funcionaris en vies de depuració que, un cop tancat el procés, va quedar extraordinàriament malmès pel que respecta a la preparació i la competència. ${ }^{23}$

Abans, per tant, d'analitzar el personal polític de referència, cal tenir en compte que, mentre els aspirants a integrar-lo passaven pel sedàs, prenia cos de manera inexorable la maquinària que hauria de governar, les característiques de la qual no enganyaven a ningú. Per tant, si resultava meridianament clar que no s'hi admetien opositors de cap mena, aquell que estava disposat a entrar en el joc i, finalment, era designat per exercir un càrrec no podia després allegar manca d'identificació amb la tasca que havia d'executar, encara menys quan el franquisme no va cercar a ningú de qui no hagués comprovat abans la fidelitat, com veurem més endavant. $\mathrm{Al}$ cap i a la fi, si el règim hagués estat prou estúpid de nomenar per a càrrecs de responsabilitat tants opositors i infiltrats que el volien liquidar, com hauria aconseguit de durar tant? L'expedient de la por de les represàlies com a motiu per acceptar un càrrec no val quan es refereix a tanta gent, perquè les represàlies les havia de prendre un governador civil que

21 Vegeu MARín, Els ajuntaments franquistes a Catalunya, 55-198.

22 Vegeu Martí Marín, «Les finances locals en el primer franquisme», dins Actes del III Congrés Internacional d'Història Local de Catalunya. Barcelona, 17-18 de novembre de 1995 (Barcelona: L’Avenç, 1996), 351-359, i Els ajuntaments franquistes a Catalunya, 159-196; Damián Alberto GoNZÁLEZ MADRID \& Juan Miguel MARTínez LozANO, «La hacienda municipal del primer Franquismo (1940-1953)», dins M.E. Nicolás Marín \& C. GonzÁlez MartíneZ, ed., Ayeres en discusión: Temas clave de Historia Contemporánea hoy, CD-ROM (Murcia: Universidad de Murcia, 2008), i Enrique Fuentes Quintana, «José Larraz» \& Manuel Jesús GonzÁlez GonZÁleZ, «Joaquín Benjumea Burín», dins Francisco Comín, ed., La Hacienda en sus ministros. Franquismo y democracia (Saragossa: Prensas Universitarias de Zaragoza, 1997), 1-14 i 15-52.

23 Més enllà de les dades de depuració —encara força incompletes-, i del seu caràcter eminentment polític, vegeu un judici tècnic a Alejandro Nieto García, «De la República a la Democracia: la Administración española del franquismo, I i II», Civitas. Revista Española de Derecho Administrativo 11 i 15 (1976 i 1977): 567-583 i 573-588. 
tenia prou feines pendents per complicar-se la vida nomenant per als càrrecs de confiança persones que no n'eren. Els governadors civils del franquisme estaven molt lluny de ser els beneits, ineficaços i només bons per reprimir, que una certa tradició popular antifranquista ha consagrat. ${ }^{24}$

Si descartem els primers mesos de pura improvisació, en el moment de prendre possessió qualsevol membre d'una comissió gestora municipal o provincial, com passava en qualsevol càrrec de l'Administració perifèrica de l'Estat a Catalunya -l'única que quedava dempeus-, sabia perfectament en quina mena d'ambient s'integrava perquè al seu voltant es multiplicaven les evidències en forma de funcionaris expulsats o sancionats de formes diverses, canvis qualitatius en els impostos, repressió multiforme i un nou estil aparatós per a les noves autoritats. Allegar, amb posterioritat, innocència del càrrec de collaboracionisme respecte d'una instauració dictatorial amb voluntat de durar, hauria d'anar acompanyat d'alguna mena de prova d'alienació mental transitòria, ja que no és possible recórrer a l'expedient de l'obligatorietat: lluny d'obligar a collaborar a algú sospitós de no voler-ho fer de gust, el règim va haver de triar entre els múltiples candidats a collaborador entusiasta, que s'organitzaven localment en colles i clienteles.

Aquesta competència per tenir l'oportunitat de collaborar, la posà de manifest la pugna aferrissada que s'establí, municipi per municipi, entre aspirants a alcaldes i regidors; una competència que, en absència de qualsevol mena d'elecció popular, es concretà en cartes acusatòries — no sempre anònimes - dels uns vers els altres, que s'adreçaren convenientment al governador civil. Denúncies similars eren recollides pels inspectors comarcals de la Falange cada vegada que el governador volia reemplaçar algú d'un càrrec o bé quan intentava treure l'aigua clara d'acusacions rebudes prèviament com les esmentades abans. Més enllà d'escrits acusato-

24 Aquesta llegenda fou alimentada per voluntaristes passats de comptes amb aquests personatges sobre la base d'un anecdotari, sovint apòcrif, guardat en la memòria popular barcelonina com ara el que recolliren J. FABre \& J.M. HuERTAS, «Els governadors civils de Barcelona», dins J. FABre, J.M. Huertas \& A. Ribas, Vint anys de resistència catalana (1939-1959) (Barcelona: La Magrana, 1978). Tanmateix, la imatge que donaven ignorava completament la política governativa de portes endins. Sobre alguns aspectes de la política desenvolupada pels governadors civils barcelonins — cruel, però no estúpida - vegeu MARín, Els ajuntaments franquistes a Catalunya i Josep Maria de Porcioles; i també Javier TÉBAR, Barcelona, anys blaus: el governador Correa Véglison. Poder y política franquistes (1940-1945) (Barcelona: Flor del Viento, 2011). 
ris, aquestes pugnes locals estaven adobades amb crits, empentes, bufetades i algun que altre tret intimidatori a l'aire, comesos en actes públics. ${ }^{25}$ Els que optaren per integrar-se en la classe política del règim a Catalunya foren, en definitiva, responsables dels seus actes. La seva opció pot tenir explicacions diverses, però de cap manera no pot sostenir-se l'explicació segons la qual les característiques del règim no eren les d'una dictadura tout court, ni tampoc la que hi havia cap possibilitat d'enganyar-se sobre quins eren els seus referents, especialment quan hom prestava atenció a les visites diplomàtiques i a la recepció que els dispensava la premsa. ${ }^{26}$

\section{Dels grups i partits polítics a les colles i les clienteles. La dinàmica política de la construcció del règim a Catalunya}

Catalunya, com la resta d'Espanya, tenia des de molt abans de la Guerra Civil un sistema de partits complex, en el qual sobresortien algunes formacions clarament consolidades a causa de la seva supervivència en el temps. En el cas català existia un món republicà i d'esquerres, més o menys nacionalista que, tot i els canvis de noms, les fusions i les escissions, havia ocupat des de principi de segle la zona esquerra del joc polític i que el 1939 havia estat desarticulat per la derrota en la guerra. En l'àmbit de la dreta hi havia hagut un únic i sòlid partit hegemònic, la Lliga Regionalista de Catalunya, Lliga Catalana des de 1933, que havia anat fagocitant els seus competidors dinàstics i havia sobreviscut amb èxit al naixement de nous partits conservadors al Principat durant la Segona República. Com ja hem esmentat, aquest partit donà suport des de ben aviat a la causa nacional. Per tant, en condicions polítiques normals, la Lliga hauria hagut de formar part de la coalició franquista amb els altres partits conservadors, ultradretans i feixistes que se li posaren al costat. S'ha escrit, amb

25 Vegeu MARÍN, Els ajuntaments franquistes a Catalunya, 84-136. Vegeu, també, una vívida narració del caos a què es va arribar en alguna població a Paco PERALTA, «La lucha por los beneficios del poder. Poder político y corrupción en la Sta. Coloma franquista (1939-1951)», Ágora. Historia de Santa Coloma de Gramenet 3 (1998): 9-34.

26 Vegeu Mireia CAPDEvila, Barcelona germànica, una ciutat acollidora per als amics alemanys. Les grans visites $i$ conferències, 1939-1945 (tesina de màster, Universitat Autònoma de Barcelona, 2010), i Oriol Sorolla, Companys i veïns. Presència del feixisme europeu al Sabadell de la postguerra espanyola (tesina de màster, Universitat Autònoma de Barcelona, 2010). 
encert, que el seu caràcter nacionalista català ho impossibilità; ${ }^{27}$ però s'ha prestat molta menys atenció, en canvi, al fet que aquest mateix destí - la dissolució forçada - afectà molts altres partits que no eren nacionalistes catalans - de fet, a la pràctica totalitat-, atès que només un partit legal va sobreviure a la guerra: FET y de las JONS. Naturalment, es pot argumentar en defensa d'una presumpta pluralitat franquista que alguns dels partits desapareguts s'havien fusionat en el nou partit únic. L'anàlisi, però, no és del tot correcta perquè aquest darrer fou producte d'una absorció forçada i no d'una unificació, i perquè no deixà de tenir les seves víctimes polítiques - la majoria dels dirigents de totes les opcions que es fusionaven quan volgueren, en algun moment, imposar condicions - , per més que la major part de la militància d'origen acabés integrada de bon grat en el nou partit. ${ }^{28}$ Com veurem, el destí de la Lliga no fou tan diferent, ja que tot i que se'n marginaren els dirigents se n'acceptaren militants dins FET-JONS, encara que hi havia una diferència, no poc important: la impossibilitat d'acceptar un partit que havia defensat un nacionalisme que no era l'espanyol com a part oficialment constitutiva del partit únic. ${ }^{29} \mathrm{Al}$ cap i a la fi, tots els militants de la nova FET-JONS, excepte els falangistes, hagueren de renunciar, també, a bona part del bagatge tradicional dels seus partits d'origen - fonamentalment la monarquia, però també el predomini de l'Església sobre el poder civil, la capacitat de manifestar la dissidència públicament, la possibilitat de l'escissió, etc. El 1939, doncs, no quedava res dempeus del sistema de partits català —ni tampoc de l'espanyol- que fes pensar que el franquisme pogués funcionar com una coalició reaccionària, el terme més emprat en els dar-

27 Vegeu Riquer, L’últim Cambó (1936-1947), 157-223.

28 Vegeu Martin Blinkhorn, Carlismo y contrarrevolución en España, 1931-1939 (Barcelona: Crítica, 1979), primera edició: Carlism and Spain. 1931-1939 (Cambridge: Cambridge University Press, 1975); Joan Maria Tнома̀s, Lo que fue la Falange. La Falange y los falangistas de José Antonio, Hedilla y la Unificación. Franco y el fin de la Falange Española de las JONS (Barcelona: Plaza \& Janés, 1999); Ismael SAZ, «Salamanca, 1937: los fundamentos de un régimen», dins Fascismo y franquismo (València: Publicacions de la Universitat de València, 2004), 125-150.

29 Per a les continuïtats de lliguers destacats dins el franquisme, vegeu RiQuer, L'últim Cambó (1936-1947),157-223. Per a un cas local que podria marcar la pauta del que s'esdevingué a altres indrets, vegeu Martí Marín, Franquisme i poder local: l'Ajuntament de Sabadell, 1939-1979 (memòria de doctorat, Universitat Autònoma de Barcelona, 1990), i Josep Lluís MARTÍn BER BOIS, La Lliga Regionalista de Sabadell o l'ocàs d'un partit (1931-1945) (Barcelona: Publicacions de l'Abadia de Montserrat, 2008). 
rers anys per referir-se al règim, ${ }^{30}$ cosa que no contradiu la idea, ja prou sabuda, que els francofalangistes procedien de molt variades formacions polítiques: "procedir de", però, no és sinònim d'“actuar com a".

Si el règim franquista hagués estat veritablement algun tipus de coalició ni a Catalunya ni enlloc del territori espanyol no s'hauria produït la mena de situació surrealista d'enfrontament entre els governadors civils i els jefes provinciales de FET-JONS ni tampoc les rèpliques a escala d'aquest mateix fenomen entre alcaldes i/o tinents d'alcalde i jefes i/o delegats locals diversos, les quals són àmpliament documentades en el memorialisme i en els estudis de recerca. ${ }^{31}$ Naturalment que hi hauria hagut enfrontaments entre partits i faccions si aquestes formacions haguessin sobreviscut d'alguna manera i haguessin defensat les pròpies posicions, cosa que hauria estat el normal; el que no hauria passat llavors és la dèria per presentar-se davant de l'autoritat superior com el més autèntic defensor del règim enfront d'un rival sobrevingut, emboscat, oportunista, corrupte, etc., tal com es va donar per tot arreu. La deslegitimació de l'adversari tingué lloc sempre a l'empara de la legitimitat que conferia haver adquirit alguna mena de document que acredités la fidelitat a la causa nacional, fins i tot abans que aquesta arribés a existir com a tal, però mai no s'emparà, en canvi, en la reivindicació d'una identitat política en contra d'una altra d'igualment anterior a 1936.

En aquesta pugna per l'autenticitat les tergiversacions i les ocultacions sobre els passats propis i aliens foren d'allò més corrents. Per això, les declaracions fetes pels interessats sobre la pròpia autenticitat i la falsedat

30 Vegeu, per exemple, Glicerio SÁnchez Recio, Sobre todos Franco. Coalición reaccionaria y grupos políticos en el franquismo (Barcelona: Flor del Viento, 2008).

31 La nota bibliogràfica que podríem fer si abastéssim el conjunt espanyol seria quilomètrica, per la qual cosa ens limitarem a alguns exemples catalans. De les tensions a la Lleida dels primers temps en parlaren, des de bàndols oposats, Emilio Romero, Tragicomedia de España. Unas memorias sin contemplaciones (Barcelona: Planeta, 1985), i Josep Maria DE PoRCIOLEs, Mis memorias (Barcelona: Editorial Prensa Ibérica, 1994), en les quals es donen versions amb què pretenien, fonamentalment, presentar-se a la posteritat com els veritablement raonables, moderns i liberals. A Girona n'ha fet una narració breu Josep CLARA, Girona sota el franquisme, 1939-1976 (Girona: Ajuntament i Diputació Provincial de Girona, 1991) i El partit únic. La Falange i el Movimiento a Girona (1935-1977) (Girona: Cercle d'Estudis Històrics i Socials, 1999). A Tarragona resulta molt més precisa l'aportació feta per Joan Maria ThомÀs, José M. Fontana Tarrats. Biografia política d'un franquista català (Reus: Edicions del Centre de Lectura, 1997). Per a una valoració global, vegeu MARín, Els ajuntaments franquistes a Catalunya, 81-136. 
de l'adversari s'han de prendre amb moltes precaucions. Atès que Falange Española i la resta de grups unificats dins FET-JONS no eren gaire més antics de 1933, qualsevol persona veterana en la política havia pogut passar per opcions que ara resultaven anatematitzades. Destriar el gra de la palla resultava complex. Els governadors civils - peça bàsica en aquest joc - tingueren molta més feina de l'esperada perquè sovint s'enfrontaven a falangistes locals que no estaven disposats a acceptar cap mena de màcula en l'historial dels seus rivals - tan o tan poc falangistes com ells, tot sovint, ja que ens referim a falangistes de FET-JONS i no de FE-JONS-, mentre que es mostraven generosos i condescendents amb les dels seus collaboradors i s'afanyaven a ocultar les pròpies. Efectivament, la resolució del conflicte mai no vingué de la mà d'un pacte entre grups polítics en igualtat de condicions, sinó de la decisió de la instància superior de govern, fos aquesta el governador civil o, arribat el cas, el ministre de la governació: successivament, Ramón Serrano Suñer (1938-1941) i Blas Pérez González (1942-1957), amb un breu interregne incolor de Valentín Galarza (1941-1942). Això és, doncs, que alguns dels més destacats membres de la nova Falange de Franco - Serrano, Pérez González- eren els que decidien en els conflictes entre grups i persones sobre qui era més autèntic - o sigui, més adequat als seus ulls. I, encara, en aquesta decisió eren assessorats per la no menys falangista Secretaría General del Movimiento. Quina mena de coalició resol les seves topades sobre la base de l'autoritat inapellable del representant d'una de les parts que, a més, és sempre la mateixa?

A la fi, bona part dels que es consideraren en algun moment derrotats en aquestes pugnes feren el possible per fer córrer dues idees: que l'individu que els havia cessat o barrat l'accés a un càrrec — de vegades el mateix governador civil - era tan sospitós de tenir un passat inadequat com els seus rivals, i que els incontestablement autèntics eren sempre els perjudicats, cosa que solia ser completament falsa, evidentment..$^{32} \mathrm{Amb}$

32 Per exemple, en una entrevista de 2002 concedida a l'historiador Ismael Saz, el falangista i alcalde de València entre 1958 i 1969 Adolfo Rincón de Arellano, explicà que en la postguerra els falangistes autèntics, com ell mateix, estaven desproveïts de poder i no pogueren fer la política que volien per culpa d'unes autoritats provincials i militars conservadores. Ismael SAz, España contra España. Los nacionalismos franquistas (Madrid: Marcial Pons, 2003), 18. Però Rafael Valls — La Derecha Regio nal Valenciana (1930-1936) (València: Alfons el Magnànim, 1992), 248-253- havia demostrat abasta- 
el ministre i els alts càrrecs del ministeri mai no gosaren fer el mateix tipus de comentaris, per motius obvis. El corollari de tot plegat és que ha arribat als historiadors uns textos memorialistics i una documentació farcida d'inexactituds - i de mentides descarades - que han pogut utilitzar-se per relativitzar o per banalitzar la pertinença a FET-JONS o l'ocupació d'un càrrec: el que un dia foren acusacions de manca de fidelitat al règim, fermament rebutjades, avui s'han pogut convertir en proves contrastades de dissidència. Cal no deixar-se enganyar per la inaudita presència de tants opositors, infiltrats i resistents dins dels rengles de la dictadura: al cap i a la fi una militància pot abandonar-se per una altra i després encara per una tercera exactament igual que una parella, sense deixar de ser més o menys coherent, d'alguna manera. Les trajectòries rectilínies són poc probables en política, en qualsevol etapa històrica que examinem, excepte en el terreny inefable de l'hagiografia.

A Catalunya, com veurem, tots aquells que havien lluitat per la victòria de Franco - fos armes en mà fos des de l'organització de la rereguarda, o treballant en activitats de cinquena columna-, estaven en la millor posició per entrar a gaudir dels fruits de la victòria, mentre que els que no podien documentar aquesta mena d'activitats perquè havien passat la guerra el més desapercebuts possible, es trobaven en un clar desavantatge. L'origen polític tant dels actius com dels passius durant la guerra era, no obstant això, molt similar: poquíssims falangistes anteriors a la guerra — com passava gairebé per tot arreu, atès el caràcter minúscul de la FE-JONS de José Antonio-, alguns monàrquics, alguns carlistes més i una munió d'individus que pertanyien o eren propers als partits majoritaris de la dreta anterior a 1936 — en aquest cas, sobretot, la Lliga Regionalista, però en altres bandes els adscrits a alguna de les organitzacions constitutives de la CEDA, com ara la Derecha Regional Valenciana. Les actituds d'uns i altres foren també molt similars: fer-se la traveta, fer protestes d'adhesión inquebrantable i, com dèiem, denunciar el passat inconvenient dels seus rivals i ocultar el propi.

ment com fou precisament el "desvalgut" Rincón de Arellano el que havia ajudat a ressituar-se en les files del règim un bon nombre de destacats conservadors de la DRV entre 1939 i 1943, quan ell ocupava el càrrec de Jefe Provincial de FET y de las JONS. 
L'única particularitat catalana en aquest marc fou que en la pugna pel poder local o comarcal resultà del més habitual acusar l'adversari de separatista, un adjectiu que no podia aplicar-se a gaires llocs més i que se sumava a la llista dels recurrents en altres indrets, com ara liberal, cacic, conservador, etc. ${ }^{33}$ Per això, i perquè qualsevol relació, ni que hagués estat de passada, amb alguna instància del multiforme catalanisme polític, cívic o cultural servia automàticament de base per a l'acusació de separatista, els conflictes entre franquistes a Catalunya poden confondre's fàcilment amb pugnes entre fidels i opositors o, com a mínim, tenyir-se aparentment d'un contingut polític més intens. Però la realitat fou molt més prosaica: tan catalanistes —o tan autèntics - solien ser els acusats com els acusadors, perquè encara que ho haguessin estat en el passat ara ja no exercien. Passada l'etapa molt inicial de les topades entre falangistes i carlistes catalans a Burgos, que es resolgueren no només amb la victòria dels primers sinó amb el canvi de bàndol de bona part dels segons, ${ }^{34}$ tota la resta d'enfrontaments interns dels primers anys de la Catalunya franquista foren per prendre posicions en el nou sistema polític, no per fer-lo anar en una o altra direcció, ja que la base no prenia aquest tipus de decisions, cosa que sabia perfectament qui volia formar-ne part: sumar-se al franquisme era pujar a un tren en marxa.

Als governadors civils els tocà la feina de decidir, sota la supervisió del Ministeri de la Governació, qui es nomenava per a cada càrrec en cada lloc. El càrrec de governador fou, per tant, la peça bàsica de tot l'entramat. Les seves decisions inapellables no foren preses per causa de la ignorància o de la improvisació. Els governadors comptaren amb l'auxili de la informació que els fou subministrada per l'organització provincial de FET-JONS i les seves delegacions locals acabades d'organitzar —d'aquí

33 Tal vegada pugui sorprendre que dins del franquisme l'acusació de cacic fos funcional, però entre els trets d'identitat del falangisme - i en força altres partits - el discurs regeneracionista i an ticaciquil desvetllador de la vella política liberal era un tòpic força estès. En aquests ambients fins i tot s'havia acusat la República de ser caciquil com la Restauració. Vegeu un exemple polític, escrit per un exjonsista, a Emiliano Aguado, La República, último disfraz de la Restauración (Madrid: Editora Nacional, 1972), i un altre de literari a càrrec del falangista Gonzalo TOR RENTE BALLESTER, Los gozos y las sombras, 3 vol. (Madrid: Arión, 1957-1962), on el típic cacic de poble que falsifica vots i sedueix donzelles és del PSOE i de la UGT.

34 Vegeu Borja de RiQuer, «Burgos 1937: divergències polítiques entre falangistes i carlins catalans", dins AA.DD, Haciendo historia: homenaje al profesor Carlos Seco (Madrid: Universidad Complutense de Madrid, 1989), i Tномѐs, Falange, Guerra Civil i franquisme, 127 i ss. 
la importància de poder acreditar autenticitat - i pels serveis d'informació de la Guàrdia Civil, molt més neutres i professionals a l'hora de subministrar dades biogràfiques d'un candidat. Això vol dir que tot i que les organitzacions locals de Falange poguessin provar de manipular el governador per collocar els seus candidats predilectes — amb o sense mèrits suficients-, aquell primer disposava d'un informe policial parallel per contrastar la informació, i mai no actuà a cegues ni es posà en mans de cap mena de cacic local aparentment totpoderós: la dinàmica fou la contrària perquè es convertia en cacic — sempre momentàniament-el que aconseguia el favor del governador. Els governadors pogueren prendre decisions equivocades o injustes si atenem a la lògica segons la qual haurien hagut de triar el personal polític més autèntic disponible, però no hi hagué ni cap equivocació ni cap injustícia en les seves decisions, i, per descomptat, cap força oculta no els manipulava des de baix: el franquisme mai no fou similar a la Restauració en aquests afers. Els governadors triaren a qui els semblà més adequat segons criteris múltiples: fidelitat contrastada al règim, però també a la jerarquia — per tant, no era molt pràctic provar d'enganyar-los-; mèrits de guerra, però també capacitat de lideratge en cada context local, etc. El resultat potser no va ser un reflex prou fidel de l'autenticitat, però sens dubte que ho fou de la fidelitat, perquè era justament el que es cercava.

Això no significà en absolut que no hi hagués directrius generals sobre quin tipus de personal polític calia privilegiar des del punt de vista del Govern, o sigui, quins criteris calia seguir per començar a cercar aquest personal fonamentalment fidel. El criteri inicial no fou - com hem anticipat - demostrar un passat polític immaculat anterior a 1936 en els partits unificats dins FET-JONS sinó provar l'adhesió al règim amb mèrits de guerra. Al cap i a la fi, haver estat monàrquic, carlista o falangista abans de 1936 no era cap garantia: es podia voler un rei o, simplement, considerar Franco un nouvingut a la política, útil per a la guerra però reemplaçable en temps de pau. Molta més garantia oferia haver-se jugat la vida en algun moment, encara que en el passat tingués alguna militància inconvenient $\mathrm{o}$, com passava més sovint, cap militància en absolut. A partir de la fidelitat de guerra jugaven la resta de criteris: la trajectòria política, òbviament, però també la posició que s'ocupava dins de la societat que caldria governar, la solvència econòmica - els càrrecs no eren retribuïts-, 
la formació, etc. Després vindria el judici de la capacitat demostrada en l'exercici, la renovació de la confiança o bé el reemplaçament: no foren pocs els que calgué apartar perquè generaven més enfrontaments dels que resolien entre les files dels fidels, perquè no eren capaços d'integrar les sensibilitats majoritàries d'entre els vencedors locals, perquè resultaren excessivament corruptes - calia, de tant en tant, donar proves d'honestedat en el món de l'estraperlo-, o perquè era necessari donar una lliçó de disciplina.

Fins ben avançada la dècada dels quaranta no es pogué donar el procés per tancat, i per això —entre d'altres coses - la implementació del sistema d'eleccions dels regidors per terços es va retardar fins al final del 1948. En aquelles dates tota la vella estructura de partits polítics catalans havia desaparegut completament - excepte en la clandestinitat-, i molt especialment la de l'espectre conservador: els partits polítics de la dreta catalana havien estat reemplaçats per un panorama atomitzat i localista de colles i clienteles sense més contactes ni organitzacions supralocals que la FET-JONS i el Govern Civil. ${ }^{35}$

Aquest panorama atomitzat no fou, però, una qüestió dels estrats baixos de la política catalana - ajuntaments i diputacions-, sinó de tota la política catalana. En primer lloc perquè el que hem descrit fins aquí es correspon amb l'única realitat política catalana possible que era la local i la provincial: Catalunya no existia administrativament i, per tant, no hi havia espai on fer política catalana per més que des d'algunes instàncies barcelonines es prengués una part pel tot quan parlaven d'elles mateixes. En segon lloc perquè els estrats superiors, econòmicament parlant, de la societat catalana se sotmeteren al règim, igual que els individus fins ara descrits: qualsevol projecte polític del passat fou abandonat per passar-se amb armes i bagatges a un règim que defensava els interessos de la propietat, havia liquidat partits i sindicats de caràcter reformista o revolucionari, havia implantat una rígida disciplina laboral segons la qual la vaga era un delicte, i s'estava sumant al que semblava que havia de ser el futur brillant de la nova Europa. Per dir-ho amb paraules de Josep (José) Pla:

35 Vegeu les reflexions de Borja de RiQuer al pròleg «De dirigents polítics a simples gestors. O com una burgesia nacional esdevingué local», dins MARÍn, Els ajuntaments franquistes a Catalunya, 11-26. 
Europa vive hoy en régimen fascista, y este régimen es fruto de un pensamiento inicial del genio político del Duce. Pero no es sólo esto. Es que el fascismo ha creado en Europa un tipo de hombre nuevo, combativo, audaz, poco amigo de las fórmulas gratuitas, enemigo implacable de las suicidas fórmulas demoliberales... Sin esta doctrina salvadora, sin estos métodos geniales, medio Continente oscilaría hoy entre el caos demoliberal y la revolución comunista. Vale la pena, me parece a mí, recordar estos hechos, porque las cosas son como son, y no como quieren que sean los dictados de una propaganda que choca con nuestra memoria inmediata de la manera más viva. Sin Mussolini, sin el fascismo, media Europa, como terreno habitable, hubiera desaparecido. ${ }^{36}$

Recapitulant, doncs: el personal polític del franquisme català fou fidel i voluntari, no pas forçat ni de circumstàncies perquè el règim s'encarregà de garbellar-lo prèviament. Aquest personal fou necessàriament conscient de quina mena de règim entrava a defensar perquè resultava del tot evident, i ho féu per consideracions econòmiques, polítiques o merament personals. Això no obstant, sempre disposà d'una alternativa: deixar-ho córrer. I si hagués volgut actuar en l'oposició, també hauria pogut; això sí, assumint els riscos que assumiren els veritables opositors, cosa a la qual molt poca gent va estar disposada. D’aquí que resulti tan convenient a algunes memòries, ara que el ametllers ja estan abatuts, pretextar que es va collaborar amb el règim per responsabilitat, per evitar que fos pitjor (?), i que va ser la seva acció la que al final va portar el règim a evolucionar democràticament, ignorant la seqüència dels fets o amagant-la rere la mort al llit del dictador i, en definitiva, obviant el que varen deixar per escrit en els arxius els mateixos franquistes sobre el pes real de la veritable oposició. ${ }^{37}$

36 José PLA, «Trascendencia de la revolución italiana», Arriba (26 des. 1940).

37 En els darrers anys, les passes donades per la recerca del període tardofranquista converteixen en patètic l'esforç per seguir pretextant en aquesta direcció, tan habitual en la transició, quan fins i tot sectors de l'oposició reconegueren, en un plantejament tàctic que esdevingué estratègic, que el paper d'una mítica oposició interna havia estat fonamental. Vegeu Pere Ysàs, Disidencia y subversión. La lucha del régimen franquista por su supervivencia, 196o-1975 (Barcelona: Crítica, 2004); Molinero \& Ysàs, La anatomía del franquismo; Xavier Domènech, Clase obrera, antifranquismo y cambio político. Pequeños grandes cambios, 1956-1969 (Madrid: Los Libros de la Catarata, 2008), un estudi fet des de la perspectiva de com es construïren les bases de la mobilització democràtica i per a la democràcia, encara que no només; Carme Molinero \& Pere Ysàs, coord., Construint la ciutat 
Fou el Govern central per mitjà dels governadors civils el que s'encarregà de destriar entre aquest conjunt d'aspirants a ocupar càrrecs en l'entramat governamental del franquisme. Ho féu seguint el criteri de la fidelitat al règim, sempre que fos possible, gràcies a l'activitat desenvolupada durant la guerra. El nomenament, però, no era per sempre sinó que, segons els resultats, hauria de ser revisat. En aquest cas, es valorà que el candidat demostrés fidelitat i respecte a la línia jeràrquica — mai no fou admissible passar per damunt del governador civil per fer qualsevol gestió a Madrid, per exemple-, així com obediència cega, capacitat de lideratge sobre el conjunt del franquisme local en el cas dels alcaldes i discreció davant de la corrupció - atès que de corruptes n'hi hagué per tot arreu, es demanava al menys que no fossin molt escandalosos. A més d'això, s'aplicaren encara altres estratègies adequades a cada moment perquè augmentés el consens amb el règim.

Tot plegat donà resultats mesurables després d'una dècada en funcionament: les dades biogràfiques dels càrrecs electes que ens permeten de fer un retrat robot o una radiografia d'aquells que foren els veritables triomfadors en el procés de construcció del franquisme català, si més no en primera instància. Aquestes dades ens donen unes primeres pistes per afrontar el tema espinós de la seva identitat política.

\section{El personal polític local. Una anàlisi del que ens diuen les xifres de la postguerra catalana}

Les dades que examinarem a continuació sobre el personal polític local del franquisme català entre 1939 i 1951 s'han obtingut dels informes elevats per FET-JONS als governs civils de les quatre províncies, la Guàrdia Civil o els ajuntaments. Es tracta d'una mostra, no pas d'una recerca exhaustiva municipi per municipi, però que engloba les persones que dirigiren bona part de la vida de la majoria de la població catalana agrupada en nuclis urbans. Les dades sobre la província de Barcelona, parcialment explotades ja en la meva tesi doctoral, ${ }^{8}$ foren localitzades a l'Arxiu del Go-

democràtica. El moviment veïnal durant el tardofranquisme i la transició (Barcelona: Icària, 2010); entre d'altres.

38 Vegeu l'apèndix d'alcaldes que figura al final de MARín, Els ajuntaments franquistes a Catalu$n y a, 495-527$, i alguns dels quadres que es recullen en aquest mateix llibre. 
vern Civil de Barcelona i corresponen a vint poblacions, totes elles caps de partit judicial, majors de 10.000 habitants o en trànsit de superar aquesta xifra. ${ }^{39}$ Les dades de les altres tres províncies tenen característiques similars però es limiten a una fotografia de l'any 1949 - amb algunes excepcions. Corresponen a vint-i-vuit poblacions i foren localitzades a l'Archivo General de la Administración (Alcalá de Henares), fonamentalment. ${ }^{\circ}{ }^{\circ}$

Respecte de les militàncies d'origen, la mostra integrada per 818 individus que ocuparen els vint ajuntaments barcelonins més els de Girona i Lleida entre 1939 i 1951 (vegeu la taula 1 de l'apèndix), ${ }^{41}$ ofereix una prova evident que es tendí menys a cercar l'autenticitat que no pas la fidelitat comprovada per mèrits de guerra. ${ }^{42}$ Aquests 818 individus presenten 291 casos de militància política —que signifiquen un total de 348 militàncies, ja que una mateixa persona en podia haver tingut dues o tres-; 141 casos del que he batejat com a militància social, un epígraf on s'agrupen els que havien tingut alguna activitat en el món catòlic o en els àmbits de sociabilitat conservadora, o que havien fet alguna collaboració amb la dreta política de forma puntual, i 386 casos més sense cap mena de militància, que representen el 47,2\% del total (vegeu el gràfic 1). Així, doncs, només un terç i escaig dels alcaldes i regidors dels principals municipis havia tingut militància abans de la guerra — cal no perdre de vista que es tracten d'àrees urbanes que havien viscut la intensa politització de la Segona República-, la qual cosa evidencia fins a quin punt la renovació fou intensa, encara més si es té en compte, primer, que aquells que són inclosos al subgrup militància social podrien sumar-se al de sense militància, i es

39 Per ordre alfabètic: Arenys de Mar, Badalona, Barcelona, Berga, Cornellà de Llobregat, Granollers, l'Hospitalet de Llobregat, Igualada, Manresa, Mataró, Sabadell, Sant Adrià de Besòs, Sant Boi de Llobregat, Sant Feliu de Llobregat, Sant Sadurní d’Anoia, Santa Coloma de Gramenet, Terrassa, Vic, Vilafranca del Penedés, i Vilanova i la Geltrú.

40 També per ordre alfabètic de cada província: Banyoles, la Bisbal d'Empordà, Blanes, Figueres, Girona, Olot, Puigcerdà, Ripoll i Santa Coloma de Farners; Balaguer, les Borges Blanques, Cervera, Lleida, Mollerussa, la Seu d'Urgell, Solsona, Sort, Tremp i Viella; Amposta, Falset, Gandesa, Montblanc, Reus, Tarragona, Tortosa, Valls i el Vendrell. Les dades de Girona capital s'han nodrit de la informació recopilada per Josep Clara, El personal polític de l'Ajuntament de Girona (1917-1987) (Girona: Cercle d'Estudis Històrics i Socials, 1987).

41 Totes les taules i gràfics a què es fa referència d'ara en endavant són a l'apèndix d'aquest article.

42 No descartem que se'ns hagin escapat alguns regidors que ocupessin el càrrec de manera molt provisional, de la mateixa manera que no hem comptabilitzat persones localitzades que exerciren només durant algunes setmanes —o dies- en els primers mesos de l'ocupació de 1939, perquè s'han considerat irrellevants. 
valora després que tan sols 51 individus havien ocupat fins llavors càrrecs polítics (vegeu el gràfic 2), cosa que vol dir que com a mínim 240 dels militants no n'havien ocupat mai cap. En aquest sentit, doncs, el quadre de renovació que se'ns presenta davant dels ulls és diàfan.

La conclusió només pot ser que en la postguerra fou relativament freqüent seleccionar persones amb passat polític actiu, però sense gaire protagonisme; és a dir, aprofitar les bases dels partits preexistents sense els seus dirigents. A més, d'entre aquestes 348 militàncies, només 162 o, el que és el mateix, només 153 dels 291 individus amb militància política havien militat en els partits que acabarien unificats per decret dins FETJONS (vegeu el gràfic 3). Així, doncs, només un 18,7\% del personal polític fou reclutat per la seva militància correcta anterior a abril de 1937, i per tant l'autenticitat no fou un valor molt més preuat que la militància en d'altres tipus de partits de l'espectre reaccionari o conservador $(16,9 \%)$ : una situació lògica si es pensa en la modèstia, ja assenyalada, dels partits que confegiren el nucli inicial de la nova FET-JONS. No obstant això, una presència propera al 20\% significà un salt quantitatiu i qualitatiu per a uns partits (FE-JONS, CT i RE) que havien tingut un pes insignificant abans de la guerra a Catalunya. Els partits que sí que havien tingut una importància real abans de la guerra, en canvi, van patir una caiguda en picat, especialment la Lliga Catalana, que passà de ser el partit hegemònic de l'espectre conservador a tenir només 85 dels 818 individus que hi haguessin militat en algun moment —això és un pobre 10,39\% (vegeu els gràfics 4 i 5). El partit clarament més beneficiat hauria estat la Comunión Tradicionalista amb els seus 95 individus (11,61\%) — tenint en compte que partia d'haver estat un soci menor de la Lliga-, si no fos perquè aquests individus havien deixat de pertànyer a aquesta formació en acceptar el carnet de FET-JONS, cosa que no feren un nombre significatiu dels seus companys, per la qual cosa van ser marginats dels càrrecs polítics. El carlista que acceptà un càrrec hagué de pagar sempre el preu de deixar-ho de ser a la pràctica, així com tota la resta d'individus hagueren de renunciar a les seves militàncies prèvies de manera constatable.

La fidelitat de guerra - allò que en algun moment he anomenat la «comunitat de la Victòria»- apareix reflectida en les 303 ocasions en què hi ha esmentat un mèrit o una circumstància vinculats a l'activitat bèllica. Aquesta situació afectà 273 individus, el 33,3\% del total. Així doncs, 
els mèrits de guerra (33,3\%) gairebé doblaren en importància les militàncies correctes de preguerra $(18,7 \%)$ a l'hora de seleccionar personal. Entre aquests mèrits, el més habitual fou el més actiu sobre el paper, el d'excombatent, circumstància que es repeteix en 145 individus, cosa que significa un $17,73 \%$ de tots els alcaldes i regidors (vegeu els gràfics 6 i 7). Aquesta darrera circumstància accentua encara més, si pot ser, la imatge de renovació, ja que haver estat combatent durant la guerra pressuposava una edat relativament jove, de la mateixa manera que accentuava també la importància dels mèrits de ser excombatent car, entre els 75 alcaldes en exercici en el període de referència, 44 presentaven mèrits de guerra (58,6\%) i 18 havien estat, precisament, excombatents (24\%).

Si comparem la informació global referida al període 1939-1951 amb la informació puntual dels consistoris de 1949 (en exercici fins a 1951), de la qual tenim referències més àmplies corresponents al conjunt de la Catalunya urbana, totes les tendències apuntades s'intensifiquen — potser excepte la qüestió dels mèrits de guerra, de la qual no tenim informació suficient. Pel que fa als orígens polítics dels membres dels consistoris (vegeu el gràfic 8), l'única diferència és que la Lliga Regionalista supera la Comunión Tradicionalista, resultat lògic de la voluntat expressada pel Ministeri de la Governació, de 1945 ençà, d'integrar un major nombre d'antics catalanistes, fins aleshores rebutjats. Seria Felipe Acedo Colunga a Barcelona, després de 1951 i, per tant, fora de la cronologia proposada, el que desenvoluparia veritablement aquesta tendència i portaria alguns antics lliguers a ocupar alcaldies tan significatives com la de Badalona (1954), Igualada (1956), l'Hospitalet de Llobregat (1952) i Vilafranca del Penedès (1952).43 Naturalment, aquesta tendència inclusiva es va iniciar per les regidories i no per les alcaldies on no hi ha un partit que aparegui com a dominant - 6 de Renovación Española, 5 de la Comunión Tradicionalista i de la Lliga, i 3 de FE-JONS i de la CEDA—, sobretot si pensem que la categoria dels municipis és desigual (vegeu el gràfic 9). Els municipis majors foren els que tingueren un personal polític amb un passat més polititzat i, encara, fou en aquests, precisament, on la presència de falangistes de preguerra resultà més accentuada (vegeu el gràfic 10).

43 Vegeu MARín, Els ajuntaments franquistes a Catalunya i Josep Maria de Porcioles. 
En termes de l'activitat de guerra - que tenim reduïda a la província de Barcelona i que, per tant, resulta més compromès de comparar-la amb les dades del període complet-, 112 de 274 regidors i alcaldes presenten mèrits de guerra, o sigui el 40,8\% que incrementaria el 33,3\% abans observat, referit a tot Catalunya. Una vegada més els excombatents són el grup majoritari, amb 56 individus que signifiquen el 20,4\% respecte del $17,7 \%$ anterior (vegeu el gràfic 11). Més significatiu és que, si considerem només els alcaldes, 17 de 20 presentin mèrits de guerra d'algun tipus i 5 siguin, precisament, excombatents (vegeu el gràfic 12). Quan la guerra més s'allunyava, sembla que més consolidada estava la generació que l'havia guanyada armes en mà: aquesta circumstància —si més no entre els alcaldes-, no començaria a canviar significativament fins als anys seixanta.

Tanmateix, en un moment ja d'estabilitat com era el 1949, el que més pistes dóna sobre el resultat del procés patit per aquest personal polític és el que tenen veritablement la majoria dels seus membres en comú: la militància dins la nova FET-JONS de la postguerra. Els gràfics 12 i 14 - els darrers ja- ens mostren com, independentment de totes les consideracions fetes sobre els orígens polítics dels regidors i dels alcaldes, el lloc on havien anat tots a parar durant la guerra i la postguerra, l'espai comú, obviant si passaven més estones o menys en els seus locals, era la Falange de Franco: un 77,3\%. Més encara, en els informes interns del partit referits a Girona, Tarragona i Lleida, la plena fidelitat al partit es calculava entre el $72,5 \%$ a Girona i el $98 \%$ a Tarragona, mentre que la immensa majoria dels que no eren considerats plenament fidels rebien la consideració de tibios con el Movimiento, i només 7 entre 309 resultaven $d u d o$ sos. Ningú no era catalogat com a indiferente o desafecto, com passaria anys més tard amb una tímida majoria ingressada en els seixanta i setanta. No hi havia notícia de cap oposició interna, ningú ja no parlava d'infiltrats conservadors o supervivències caciquils, i ja no es rebien les cartes acusadores de la immediata postguerra o no se'n feia cap mena de cas.

La identificació amb la Falange, com a divisa comuna dels vencedors, i amb la dictadura carismàtica de Franco, auxiliat pels engranatges del partit únic com a sistema, resulten els valors més segurs a l'hora de rastrejar la identitat dels franquistes catalans de la postguerra. Amb independència de les seves evolucions posteriors, els trets de dissidència encara no s'havien manifestat per enlloc, ni tan sols els d'heterodòxia. Si 
aquestes observacions finals no fossin correctes i fos veritable la llegenda d'un franquisme català dèbil, fet de persones de bona voluntat fonamentalment obligades, sense cap mena d'entusiasme ni pel règim en general ni pel Movimiento en particular, només podríem explicar l'existència de la documentació recopilada fins aquí suposant que la Falange es mentia a ella mateixa tant en informes personals com en recopilacions estadístiques -delegació local per delegació local-, i que comptava per a aquesta maniobra gegantina de falsificació amb el suport d'una Guàrdia Civil que enganyava sistemàticament el Ministeri de la Governació. I tot plegat per a què, si era documentació només per al consum intern i estava destinada a ser vista globalment per una dotzena de persones a tot estirar? Per avorriment?, per esport?, o amb l'objectiu sibillí d'enganyar els historiadors del futur? Aquestes hipòtesis em resulten molt aventurades, per no dir una altra cosa. 


\section{APÈNDIX}

Taula I. Militància d’origen, anterior a l'abril de 1937, del personal polític de 22 dels principals municipis catalans, 1939-1951

\begin{tabular}{|c|c|c|c|c|c|c|c|c|c|}
\hline & 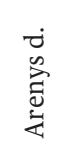 & 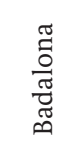 & 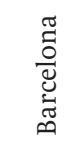 & 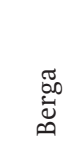 & 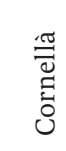 & 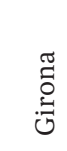 & 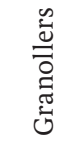 & 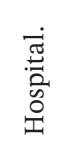 & 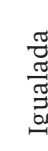 \\
\hline FE-JONS & & 2 & 9 & 1 & 5 & 1 & 1 & 1 & 1 \\
\hline Comunión Tradicionalista & & 8 & 13 & 1 & 4 & 5 & 5 & 3 & 10 \\
\hline Lliga Catalana & 1 & 8 & 8 & 2 & 2 & 2 & 10 & 1 & \\
\hline Renovación Española & 6 & 2 & 5 & & & 1 & 1 & & 1 \\
\hline CEDA & & & 2 & 6 & & 2 & 1 & 1 & 1 \\
\hline Unión Patriótica & & 2 & 5 & 3 & & 3 & 2 & 1 & \\
\hline Unión Monárquica Nacional & & & 2 & & & & & & \\
\hline Partit Republicà Radical & & 1 & & & 2 & & 1 & 1 & \\
\hline Partit Catalanista Republicà & & 2 & & & & & & & \\
\hline ERC & & 1 & & & & & & & \\
\hline \multicolumn{10}{|l|}{ UGT } \\
\hline \multicolumn{10}{|l|}{ Unió Democràtica de Catalunya } \\
\hline \multicolumn{10}{|l|}{ PCE } \\
\hline Unió Socialista de Catalunya & & & 1 & & & & & & \\
\hline Monàrquic & & & 4 & 1 & & & & & 2 \\
\hline $\begin{array}{l}\text { Total militàncies polítiques } \\
\text { (individus) }\end{array}$ & $\begin{array}{r}7 \\
(7)\end{array}$ & $\begin{array}{r}26 \\
(18)\end{array}$ & $\begin{array}{r}49 \\
(42)\end{array}$ & $\begin{array}{r}14 \\
(12)\end{array}$ & $\begin{array}{r}13 \\
(12)\end{array}$ & $\begin{array}{r}14 \\
(14)\end{array}$ & $\begin{array}{r}21 \\
(17)\end{array}$ & $\begin{array}{r}8 \\
(6)\end{array}$ & $\begin{array}{l}15 \\
(9)\end{array}$ \\
\hline Catalanista & & 1 & & & & & 1 & & \\
\hline Catòlic & & & & 2 & 1 & 1 & 3 & 2 & 9 \\
\hline Dretes & & & 2 & 3 & 3 & 11 & 1 & 4 & 7 \\
\hline Total militàncies socials & & 1 & 2 & 5 & 4 & 12 & 5 & 6 & 16 \\
\hline Sense militància & 13 & 22 & 18 & 7 & 16 & 11 & 11 & 39 & 3 \\
\hline Total individus & 20 & 41 & 62 & 24 & 32 & 37 & 33 & 51 & 28 \\
\hline
\end{tabular}




\begin{tabular}{|c|c|c|c|c|c|c|c|c|c|c|c|c|c|}
\hline 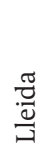 & 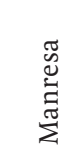 & 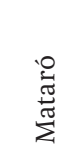 & $\begin{array}{l}\overline{0} \\
\overrightarrow{0} \\
\overrightarrow{0} \\
\tilde{\pi} \\
\tilde{\omega}\end{array}$ & 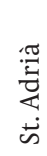 & $\begin{array}{l}\overrightarrow{0} \\
\infty \\
\dot{\omega}\end{array}$ & $\begin{array}{l}\vec{\Xi} \\
\dot{0} \\
\dot{\omega}\end{array}$ & 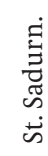 & 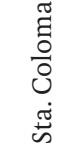 & 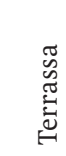 & $\stackrel{0}{>}$ & 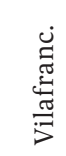 & 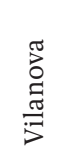 & 舁 \\
\hline 2 & 2 & & 4 & & 1 & & & 1 & 2 & 2 & & 1 & 36 \\
\hline 2 & 13 & 6 & 4 & 1 & & 1 & & 3 & 7 & 4 & 2 & 3 & 95 \\
\hline 1 & 4 & 11 & 9 & & 9 & 1 & 1 & 7 & 2 & 1 & 1 & 4 & 85 \\
\hline 1 & 2 & & & & & & & & 10 & 2 & & & 31 \\
\hline \multirow[t]{11}{*}{1} & 4 & 5 & 4 & & & 1 & & & & 1 & 4 & 1 & 34 \\
\hline & 2 & 3 & 3 & & 3 & & 2 & 1 & 1 & & 1 & & 32 \\
\hline & & & & & 1 & & & & 1 & & & & 4 \\
\hline & & 2 & & & & & & & & & & & 7 \\
\hline & & & & & & & & & & & 2 & & 4 \\
\hline & & & & & & & & 1 & & & & & 2 \\
\hline & 3 & & & & & & & & & & & & 3 \\
\hline & & & 1 & & & & & & & & & & 1 \\
\hline & & & & & & & & 1 & & & & & 1 \\
\hline & & & & & & & & & & & & & 1 \\
\hline & & & 1 & & & & & 1 & & & 2 & 1 & 12 \\
\hline \multirow[t]{2}{*}{$\begin{array}{r}7 \\
(6)\end{array}$} & $\begin{array}{r}30 \\
(26)\end{array}$ & $\begin{array}{r}27 \\
(23)\end{array}$ & $\begin{array}{r}26 \\
(20)\end{array}$ & $\begin{array}{r}1 \\
(1)\end{array}$ & $\begin{array}{r}14 \\
(10)\end{array}$ & $\begin{array}{r}3 \\
(3)\end{array}$ & $\begin{array}{r}3 \\
(2)\end{array}$ & $\begin{array}{r}15 \\
(14)\end{array}$ & $\begin{array}{r}23 \\
(20)\end{array}$ & $\begin{array}{l}10 \\
(9)\end{array}$ & $\begin{array}{r}12 \\
(11)\end{array}$ & $\begin{array}{l}10 \\
(9)\end{array}$ & $\begin{array}{r}348 \\
(291)\end{array}$ \\
\hline & & & & & & & & & & & & 1 & 3 \\
\hline 2 & 2 & 3 & 2 & 1 & 1 & 4 & & & 2 & & 4 & 6 & 45 \\
\hline 12 & 2 & 4 & 3 & 6 & & 2 & 1 & 4 & 4 & 7 & 12 & 5 & 93 \\
\hline 14 & 4 & 7 & 5 & 7 & 1 & 6 & 1 & 4 & 6 & 7 & 16 & 12 & 141 \\
\hline 17 & 22 & 33 & 13 & 9 & 21 & 20 & 12 & 18 & 24 & 22 & 23 & 12 & 386 \\
\hline 37 & 52 & 63 & 38 & 17 & 32 & 29 & 15 & 36 & 50 & 38 & 50 & 33 & 818 \\
\hline
\end{tabular}


Gràfic 1. Formes de militància anterior a la guerra dels membres dels consistoris catalans urbans 1939-1951

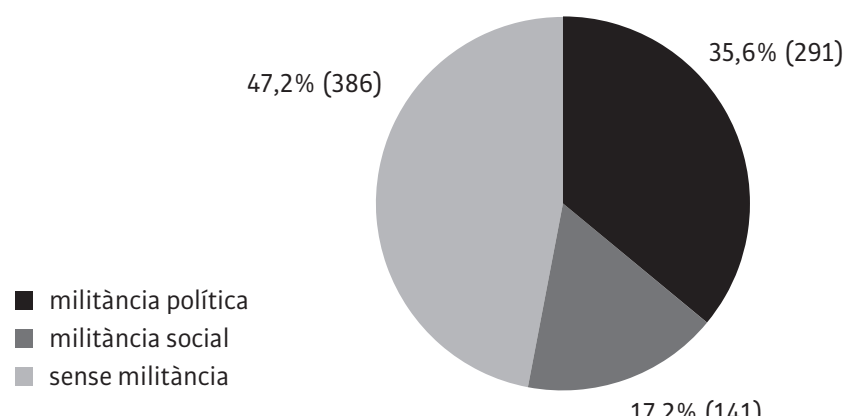

Gràfic 2. Experiència anterior dels membres dels consistoris catalans urbans 1939-1951 (\% sobre el total)

\begin{tabular}{l|l} 
Segona República & 2,6\% \\
Dictablanda & 1,8\% \\
Dictadura & $0,6 \%$ \\
Monarquia liberal & $0,9 \%$ \\
Sense precisar &
\end{tabular}

Total amb experiència 
Gràfic 3. Formes de militància anterior a la guerra dels membres dels consistoris catalans urbans II 1939-1951

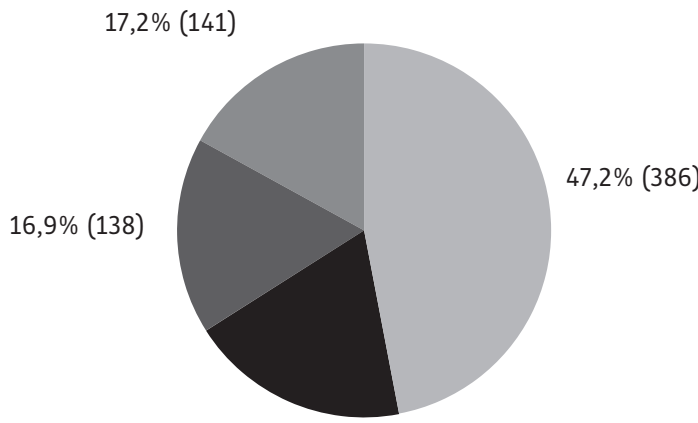

$18,7 \%(153)$

Gràfic 4. Militància política anterior a l'abril de 1937 dels membres dels consistoris catalans urbans 1939-1951

- FE-JONS

- Comunión Tradicionalista (CT)

- Lliga Regionalista (LIRC)

- Renovación Española (RE)

- APC/CEDA

- Unión Patriótica (UP)

- Monàrquics liberals

- Monàrquics conservadors

Esquerres

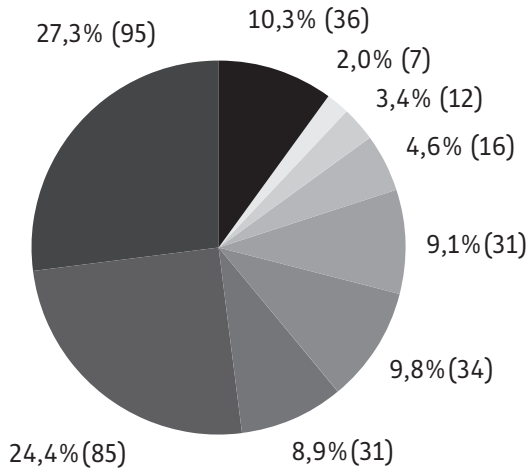


Gràfic 5. Militància política anterior a la guerra dels membres dels consistoris catalans urbans 1939-1951 (\% sobre el total)

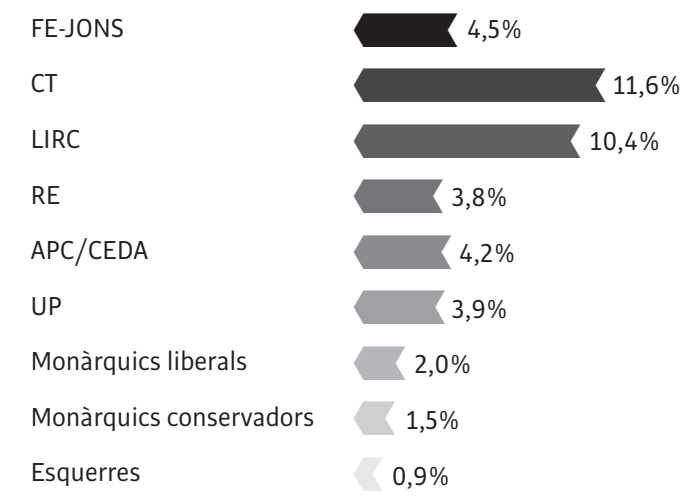

Gràfic 6. Activitats de guerra dels membres dels consistoris catalans urbans 1939-1951

Excombatents

- Excaptius

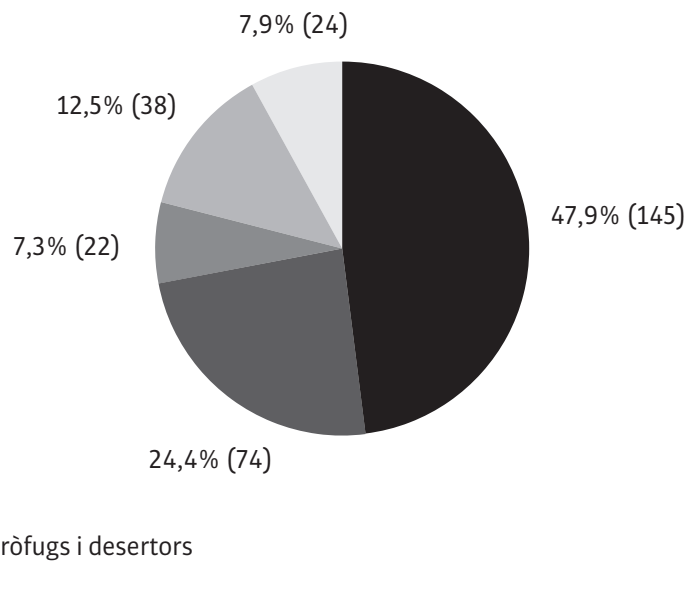


Gràfic 7. Activitats de guerra dels membres dels consistoris catalans urbans $1939-1951$ (\% sobre el total)

Excombatents

Excaptius

Familiars del caigut

Rereguarda, exiliats, pròfugs i desertors 5a columna

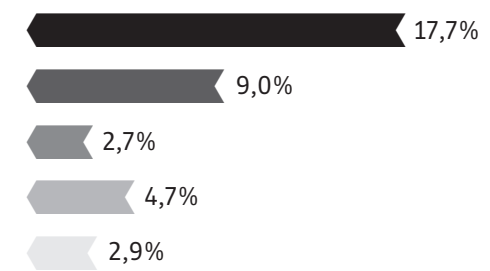

Gràfic 8. Militància anterior a l'abril de 1937 dels membres dels consistoris catalans urbans de 1949

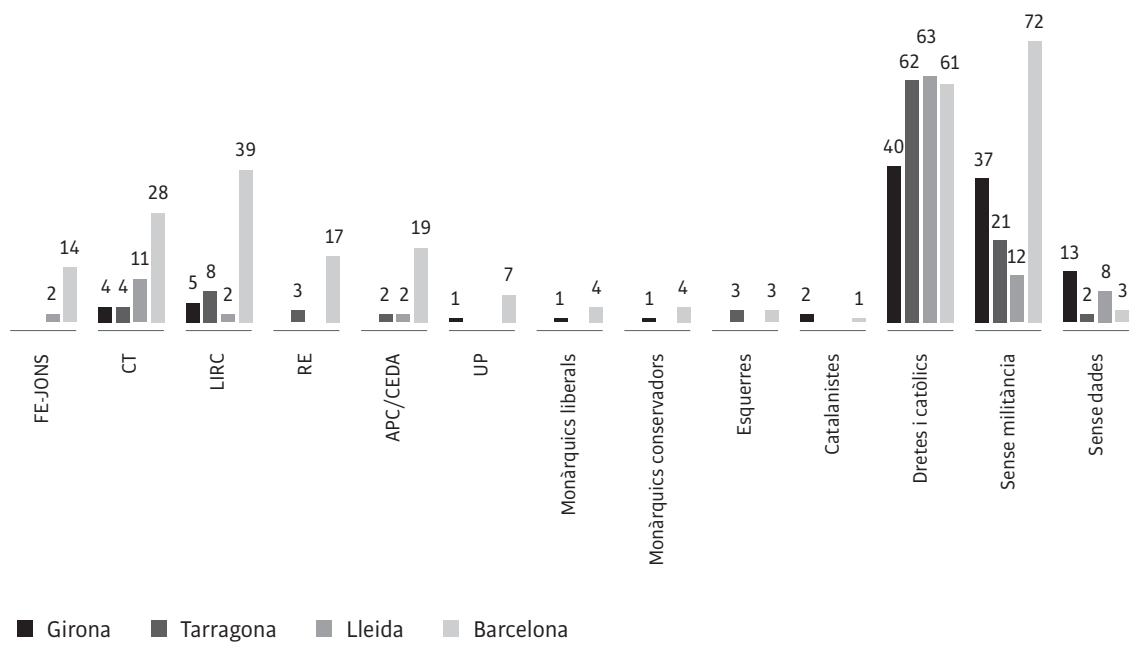


Gràfic 9. Militància anterior a l'abril de 1937 dels alcaldes dels consistoris catalans urbans de 1949

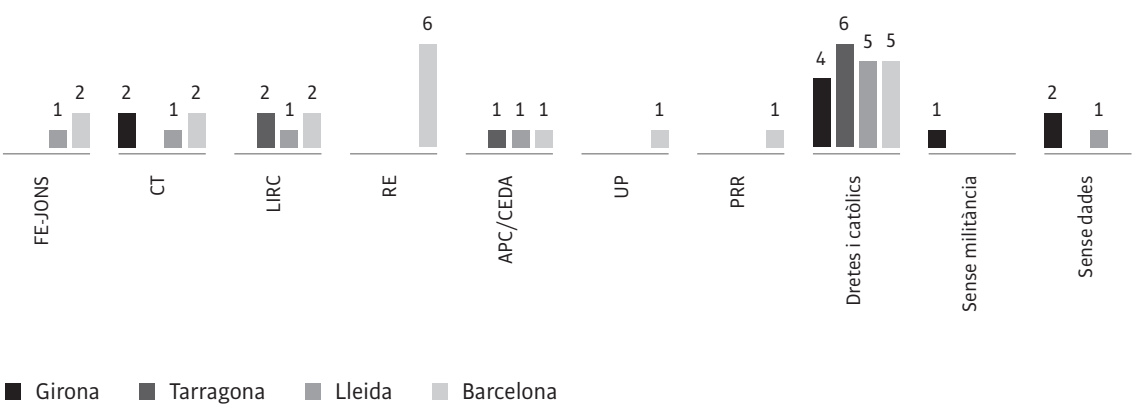

Gràfic 10. Militància anterior a l'abril de 1937 dels membres dels consistoris catalans urbans de 1949 (per mida dels municipis)

Municipis de 18 o més regidors (63)

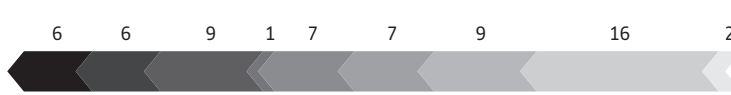

Municipis de 15 regidors (142)

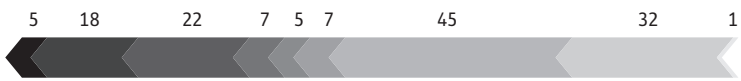

Municipis de 12 regidors (117)

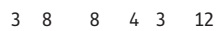

49

$26 \quad 3$
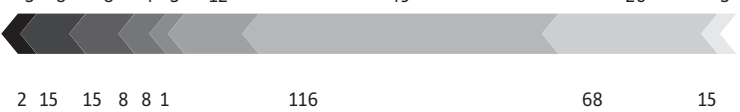

116

68

15

Municipis de 9 regidors (248)

Municipis de 6 regidors (140)

Total (583)

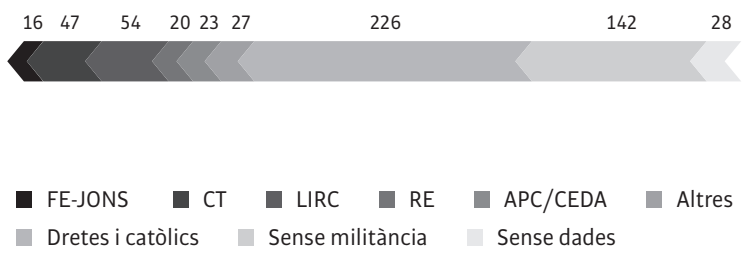


Gràfic 11. Activitats de guerra dels membres dels consistoris urbans de Barcelona de 1949 (d'un total de 274)

\author{
Excombatents \\ Excaptius \\ Familiars del caigut \\ Rereguarda, exiliats, pròfugs i desertors \\ 5a columna
}

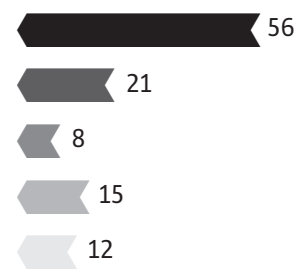

56

Gràfic 12. Activitats de guerra dels alcaldes dels consistoris urbans de la província de Barcelona de 1949 (d'un total de 20)

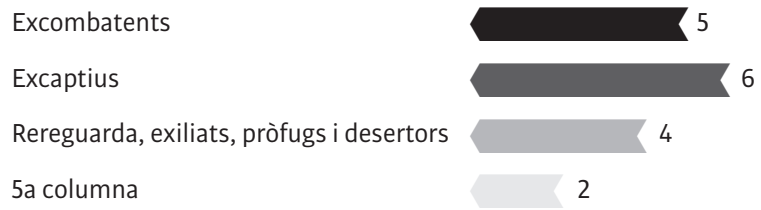

Gràfic 13. Militància dins de les FET-JONS dels membres dels consistoris urbans catalans de 1949

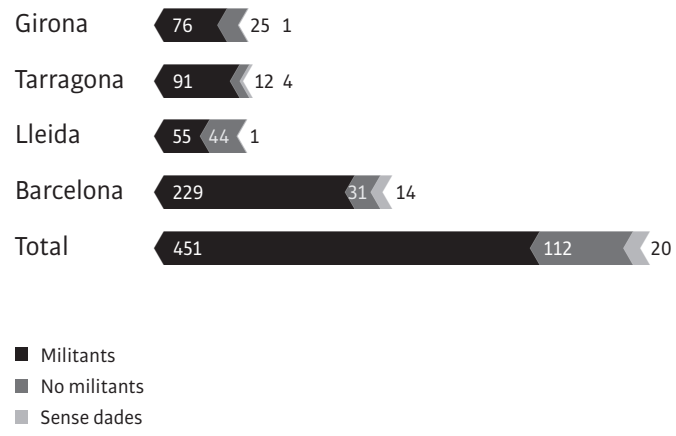


Gràfic 14. Actitud envers les FET-JONS dels membres dels consistoris urbans catalans de 1949 (segons les FET-JONS)

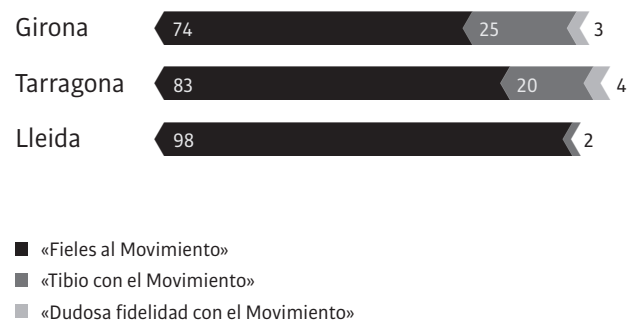

